\title{
Actualities and Development of Heavy-Duty CNC Machine Tool Thermal Error Monitoring Technology
}

\author{
Zu-De Zhou ${ }^{1,2,3} \cdot$ Lin Gui ${ }^{4}$ Yue-Gang Tan ${ }^{1,2,3} \cdot$ Ming-Yao Liu ${ }^{1,2,3}$ • \\ Yi Liu ${ }^{1,2,3} \cdot$ Rui-Ya $\mathbf{L i}^{1,2,3}$
}

Received: 6 April 2016/Revised: 21 April 2017/Accepted: 6 July 2017/Published online: 25 July 2017

(c) The Author(s) 2017. This article is an open access publication

\begin{abstract}
Thermal error monitoring technology is the key technological support to solve the thermal error problem of heavy-duty CNC (computer numerical control) machine tools. Currently, there are many review literatures introducing the thermal error research of CNC machine tools, but those mainly focus on the thermal issues in small and medium-sized CNC machine tools and seldom introduce thermal error monitoring technologies. This paper gives an overview of the research on the thermal error of $\mathrm{CNC}$ machine tools and emphasizes the study of thermal error of the heavy-duty $\mathrm{CNC}$ machine tool in three areas. These areas are the causes of thermal error of heavy-duty CNC machine tool and the issues with the temperature monitoring technology and thermal deformation monitoring technology. A new optical measurement technology called the "fiber Bragg grating (FBG) distributed sensing technology" for heavy-duty CNC machine tools is introduced in detail. This technology forms an intelligent sensing and monitoring system for heavy-duty CNC machine tools. This paper fills in the blank of this kind of review articles
\end{abstract}

Supported by National Natural Science Foundation of China (Grant No. 51475343), and International Science and Technology Cooperation Program of China (Grant No. 2015DFA70340).

Rui-Ya Li

liruiya@whut.edu.cn

1 School of Mechanical and Electronic Engineering, Wuhan University of Technology, Wuhan 430070, China

2 WHUT-Birmingham University Intelligent Machine Joint Laboratory, Wuhan 430070, China

3 Hubei Digital Manufacturing Key Laboratory, Wuhan 430070, China

4 Wuhan Heavy Duty Machine Tool Group Corporation, Wuhan 430070, China to guide the development of this industry field and opens up new areas of research on the heavy-duty CNC machine tool thermal error.

Keywords Heavy-duty CNC machine tool - Thermal error · Temperature field · Deformation field · Fiber Bragg grating

\section{Introduction}

The history of the study of the machine tool thermal error is close to a century long. There is still no solution to the thermal error problem with modern high precision $\mathrm{CNC}$ machine tools. Most research about the machine tool thermal error has focused on establishing the relationship between the temperature field and thermal error of machine tools, but no solutions have presented themselves well in industry application. Since there have been no new technological breakthroughs in the experimental studies on the thermal error, traditional electrical testing and laser measurement technology are commonly used. The research objects in thermal error testing are usually small and medium-sized CNC machine tools. There is relatively less research on heavy-duty $\mathrm{CNC}$ machine tools.

Heavy-duty CNC machine tools are pivotal pieces of equipment in many advanced manufacturing industries, such as aerospace, energy, petrochemicals, rail transport, shipbuilding, and ocean engineering. They are widely used in the machining of large parts and high-end equipment, such as steam turbines, large nuclear pumps, marine propellers, and large aircraft wings [1]. Improving the machining precision of heavy-duty CNC machine tools is of great significance to comprehensively improving the efficiency of steam turbine units, extending the life of the 
nuclear power shaft system, reducing the noise of submarine propulsion, reducing the resistance of flight, and so on. The machining error of heavy-duty CNC machine tools can be classified into five parts:

(1) Geometric errors produced by machine parts' manufacturing and assembly;

(2) Thermal-induced deformation errors caused by internal and external heat sources;

(3) Force-induced deformation errors caused by the cutting force, clamping force, machine tool's own gravity, etc.;

(4) Control errors caused by issues such as the response lag, positioning detection error of the servo system, $\mathrm{CNC}$ interpolation algorithm, etc.;

(5) Tool wear and the high frequency flutter of the machine tool.

The proportion of the thermal deformation error is often the largest for high precision CNC machine tools. In precision manufacturing, the thermal deformation error accounts for about $40 \%-70 \%$ of the total machining errors [2]. In 1933, the influence of heat on precision part processing was noticed for the first time [3]. A number of qualitative analysis and contrast tests were carried out between the 1930s and the 1960s. Until the 1970s, researchers used the finite element method (FEM) for machine tool thermal deformation calculations and the optimization of the design of machine tools. The CNC thermal error compensation technology appeared in the late 1970s. After the 1990s, thermal error compensation technology rapidly developed, and many research institutions conducted in-depth studies on the thermal error compensation technology of CNC machine tools based on temperature measurements [4-14].

As shown in Figure 1, the ideology of real-time compensation of thermal error for CNC machine tool consists of two steps. First, extensive experiments are carried out on the CNC machine tools, that collect the CNC data, body temperature of the machine tool, ambient temperature, and the thermal error of the cutting tool tip, in order to establish the thermal error prediction models that are always the multiple linear regression (MLR) model, artificial neural network(ANN) model, and genetic algorithm(GA) model, etc.(shown in Figure 1(a)). Then, the established thermal error prediction model is applied on the CNC machine tool to make error compensation at the tool center point (TCP) through the real-time $\mathrm{CNC}$ data and temperature data (shown in Figure 1(b)).

Over the past few decades, the International Organization for Standardization (ISO) promulgated a series of standards: ISO 230-3 (thermal deformation of the machine tool) [15], ISO 10791-10 (thermal deformation of the machining center) [16], and ISO 13041-8 (thermal distortion of the turning center) [17]. These standards provide systemic analysis methods for machine tool thermal behavior.

Compared to small and medium-sized CNC machine tools, heavy-duty $\mathrm{CNC}$ machine tools have unique structural and thermal characteristics, including the following items:

(1) Larger and heavier moving parts, like the spindle box, moving beam, and moving workbench;

(2) Larger and more complex support structures, such as the machine tool base, column, and beam;

(3) More decentralized internal heat sources in 3-D (3dimensional) space;

(4) Greater susceptibility to environmental temperature shifts.

As the temperature varies over time and the moving parts are heavy, the thermal and mechanical errors exist a strong coupling effect, making the thermal deformation mechanism more complicated and the optimization of the structural design more difficult. As heavy-duty CNC machine tools are more susceptible to environmental temperature shifts (due to the large volume, small changes of environmental temperature can cause noteworthy accumulations of thermal expansion of the machine tool structure in 3-D space), the robustness of the thermal error prediction model of heavy-duty $\mathrm{CNC}$ machine tools is more difficult to control.

Monitoring technologies related to the thermal error study of heavy-duty CNC machine tools are important foundation of the research on the machine tool thermal error mechanism and the establishment of a thermal error prediction model. These monitoring technologies include the temperature field monitoring technologies and the thermal deformation monitoring technologies. Further, the thermal deformation monitoring consists of the position error monitoring of the cutting tool tip and the thermal deformation field monitoring of the large structural parts of the machine tool. Because of the unique structural and thermal characteristics of the heavy-duty $\mathrm{CNC}$ machine tools mentioned above, there are lots of differences between the heavy-duty machine tool and other machine tools for thermal error monitoring, which can be concluded in three aspects:

(1) In terms of temperature field monitoring, as heavyduty CNC machine tools have a large volume and dispersive heat sources, more temperature measuring points are needed in order to establish an accurate temperature field distribution. Additionally, the installation positions of temperature sensors are more difficult to determine, and the optimization of the temperature measuring points is more complex; 


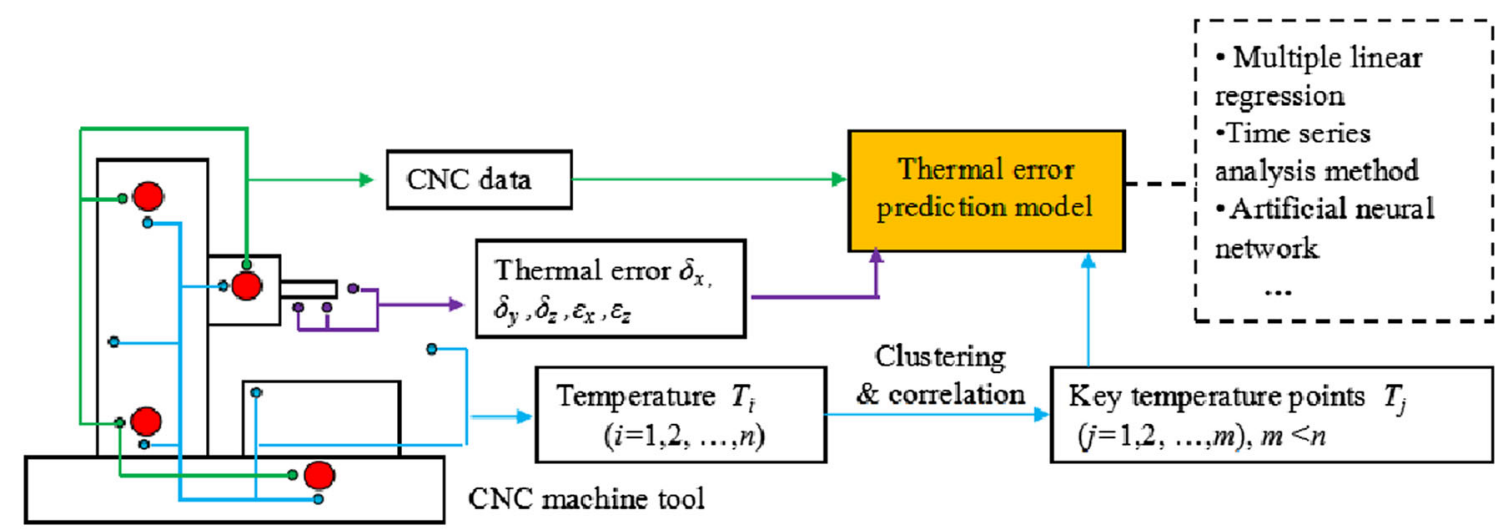

(a) Establishing the thermal error prediction model

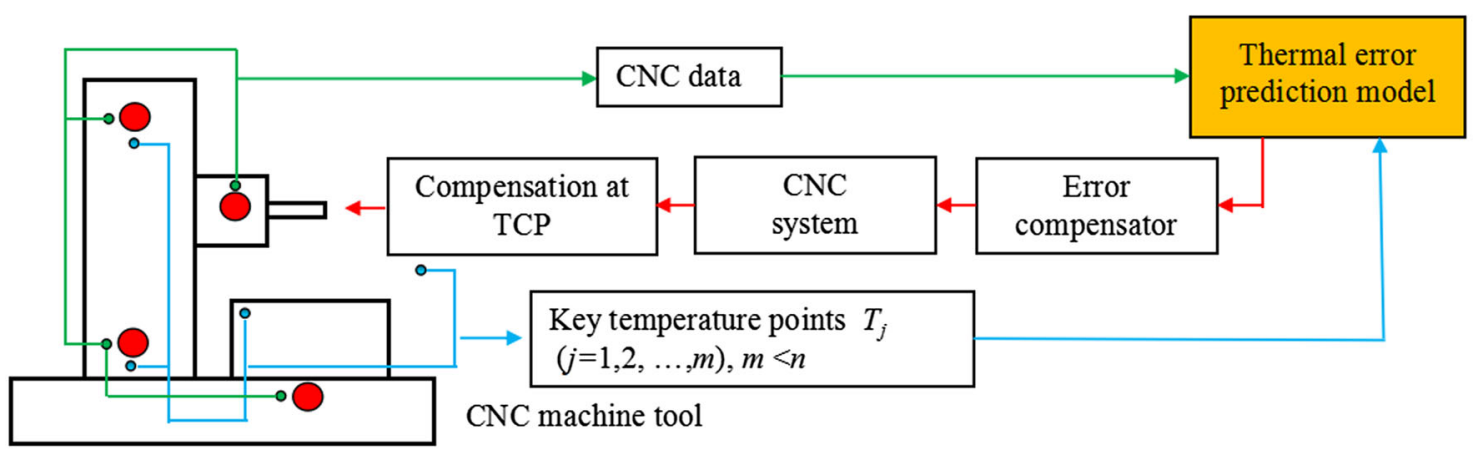

(b) Real-time compensation of thermal error

Figure 1 Ideology of real-time compensation of thermal error for $\mathrm{CNC}$ machine tool

(2) In terms of thermal deformation monitoring, there are lots of similarity in position error monitoring of the cutting tool tip between the heavy-duty machine tool and other machine tools. However, for thermal deformation field monitoring of the large structural parts, the Heavy-duty CNC machine tools face greater challenges. The existing machine tool deformation detection techniques are mostly based on the displacement detection instruments, which only detect one point or a few points' displacement of the machine tool structure. These methods estimate the deformation by the interpolation method. As the structural parts of the heavy-duty $\mathrm{CNC}$ machine tool are larger, more conventional displacement sensors or displacement measurement instruments with wide measurement range in the space are needed to reconstruct the whole thermal deformation of the structures. Additionally, as the moving parts of the heavy-duty $\mathrm{CNC}$ machine tool are rather heavier than the small and medium-sized CNC machine tools, when the machine tool works, the sedimentation deformation and vibration of the reinforced concrete foundation is more serious and intractable, which reduces the displacement measurement accuracy directly;

(3) The processing environment of heavy-duty CNC machine tool is generally worse than the small and medium-sized CNC machine tools. Traditional electric sensors can be easily influenced by the work environment. Humidity, dust, oil pollution, and electromagnetic interference all reduce the sensors' performance stability and reliability. The long-term thermal error monitoring of the heavyduty CNC machine tools requires better environmental adaptability and higher reliability to the related sensors.

In order to solve the thermal issues of heavy-duty $\mathrm{CNC}$ machine tools, we need to analyze the causes of thermal error of machine tool and then carry out in-depth study on the thermal deformation mechanism based on the existing theory and thermal deformation detection technology. In addition, we need to conclude the existing monitoring technologies and provides new technical support for thermal error research on heavy-duty CNC machine tools.

Currently, there are many review literatures on the thermal error of CNC machine tools [2, 18-26], but these 
papers mainly focus on the thermal issues in small and medium-sized CNC machine tools and seldom introduce thermal error monitoring technologies. This paper focuses on the study of thermal error of the heavy-duty CNC machine tool and emphasizes on its thermal error monitoring technology. First, the causes of thermal error of the heavy-duty CNC machine tool are discussed in Section 2, where the heat generation in the spindle and feed system and the environmental temperature influence are introduced. Then, the temperature monitoring technology and thermal deformation monitoring technology are reviewed in detail in Sections 3 and 4, respectively. Finally, in Section 5, the application of the new optical measurement technology, the "fiber Bragg grating distributed sensing technology" for heavy-duty CNC machine tools is discussed. This technology is an intelligent sensing and monitoring system for heavy-duty CNC machine tools and opens up new areas of research on the heavy-duty CNC machine tool thermal error.

\section{Causes of Thermal Error of Heavy-Duty CNC Machine Tool}

\subsection{Classification of the Heat Sources}

The fundamental causes of thermal error of the heavy-duty CNC machine tool are related to the internal and external heat sources.

\section{(1) Internal heat sources}

Heat generated from friction in the spindle, ball screws, gearbox, guides, and other machine parts; Heat generated from the cutting process; Heat generated from energy loss in the motors, electric circuits, and hydraulic system; Cooling influences provided by the various cooling systems.

\section{(2) External heat sources}

Environmental temperature variation; Thermal radiation from the sun and other light sources.

For the internal heat sources, the heat generated from the spindle and ball screws has a significant influence on the heavy-duty $\mathrm{CNC}$ machine tools and appears frequently in the literatures. The heating mechanism, thermal distribution, and thermal-induced deformation are often researched by theoretical and experimental methods. For the external heat sources, the dynamic change regularity of the environmental temperature and its individual influence and combined effects with internal heat sources on thermal error of heavy-duty CNC machine tools are studied.

\subsection{Heat Generated in the Spindle}

\subsubsection{Thermal Model of the Supporting Bearing}

The thermogenesis of the rolling bearings, namely the rolling bearing power loss $N_{\mathrm{f}}$ is generally calculated by taking the rolling bearing as a whole. It is the scalar product of the rolling bearing friction torque $M_{\mathrm{f}}$ and angular velocity of the inner ring of the bearing.

$N_{\mathrm{f}}=M_{\mathrm{f}} \cdot \pi \cdot n_{i} / 30$,

where $n_{i}$ is the rotating speed of the spindle in Eq. (1).

Palmgren [27, 28] developed the experiential formula for the rolling bearing friction torque $M_{\mathrm{f}}$ based on experimental tests:

$M_{\mathrm{f}}=M_{\mathrm{l}}+M_{\mathrm{v}}$,

$M_{1}=f_{1} P_{1} D_{\mathrm{m}}$,

$M_{\mathrm{v}}=\left\{\begin{array}{lc}10^{3}\left(v n_{i}\right)^{\frac{2}{3} D_{\mathrm{m}}^{3}}, & v n_{i} \geq 2 \times 10^{-3}, \\ 16 f_{0} D_{\mathrm{m}}^{3}, & v n_{i}<2 \times 10^{-3},\end{array}\right.$

where $M_{1}$ and $M_{\mathrm{v}}$ are the load friction torque and viscous friction torque respectively in Eq. (2), $D_{\mathrm{m}}$ is the pitch diameter of the bearing, and $v$ is the kinematic viscosity of the lubricating oil. $f_{0}, f_{1}$ and $P_{1}$ are related to the bearing type in Eqs. (3) and (4). Atridage [29] modified Palmgren's equation to take the effect of the lubricating oil flow into consideration. Stein and $\mathrm{Tu}$ [30] modified Palmgren's equation to consider the effect of the induced thermal preload.

The above models calculate the thermogenesis value of the rolling bearing as a whole, and they do not involve the the surface friction power loss calculation of the inner concrete components of the bearing. Rumbarger, et al. [31], used the established fluid traction torque model to calculate the friction power loss of the bearing roller, cage, and inner and outer ring raceway respectively. But their model ignored the heating mechanism differences between the local heat sources. Chen, et al. [32], calculated the total thermogenesis of the bearing from the local heat sources with different heating mechanisms. Moorthy and Raja [33] calculated the thermogenesis value of the local heat sources, they also took into consideration the change in the diametral clearance after the assembly and during operation that was attributed to the thermal expansion of the bearing parts, which influenced the gyroscopic and spinning moments contributing to the heat generation. Hannon [34] detailed the existing thermal models for the rolling-element bearing.

\subsubsection{Thermal Distribution in the Spindle}

When studying the temperature field distribution of the spindle, the cause-and-effect model and power flow model 
should first be analyzed, to determine the heat sources and heat transfer network. Then the heat transfer parameters should be determined, including heat transfer coefficients of the materials, thermal contact resistances between the contact surface, and heat transfer film coefficients. The heat transfer coefficients are easier obtained relatively. The thermal contact resistances between the contact surfaces are concerned with the surface roughness and contact force, and are often obtained by experimental methods [35]. Heat convection within the housing is the most difficult to describe, so a rough approximation is often used for the heat transfer film coefficient [28].

$h_{\mathrm{v}}=0.0332 \mathrm{kPr}^{1 / 3}\left(\frac{u_{\mathrm{s}}}{v_{0} x}\right)^{1 / 2}$,

where $u_{\mathrm{s}}$ equals the bearing cage surface velocity, $x$ equals the bearing pith diameter, $v_{0}$ represents the kinematic viscosity and $P r$ is the Prandtl number of the oil in Eq. (5). It is important to note that for different heat convection objects, the transfer film coefficients have different expression formulas.

Bossmanns and $\mathrm{Tu}[36,37]$ illustrated the detailed causes and effects of the spindle variables (shown in Figure 2), presented the power flow model (shown in Figure 3), and developed a finite difference thermal model to characterize the power distribution of a high speed motorized spindle. The heat transfer coefficients, thermal contact resistances, and heat convection coefficients were all calculated in their analytical method in

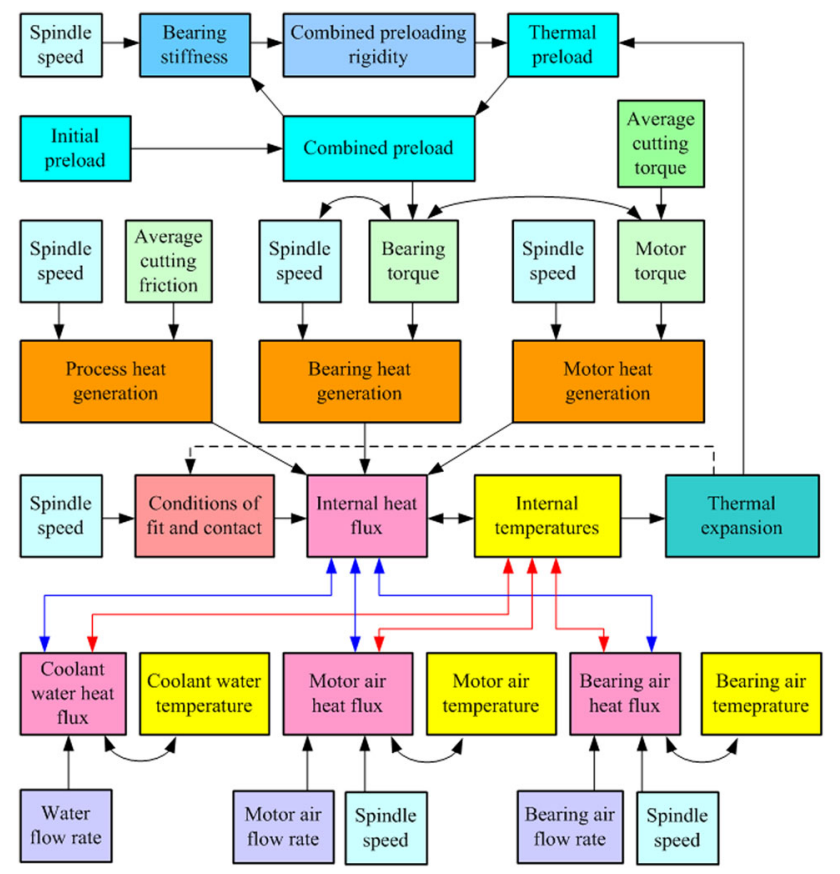

Figure 2 Cause-and-effect model for spindle [36]

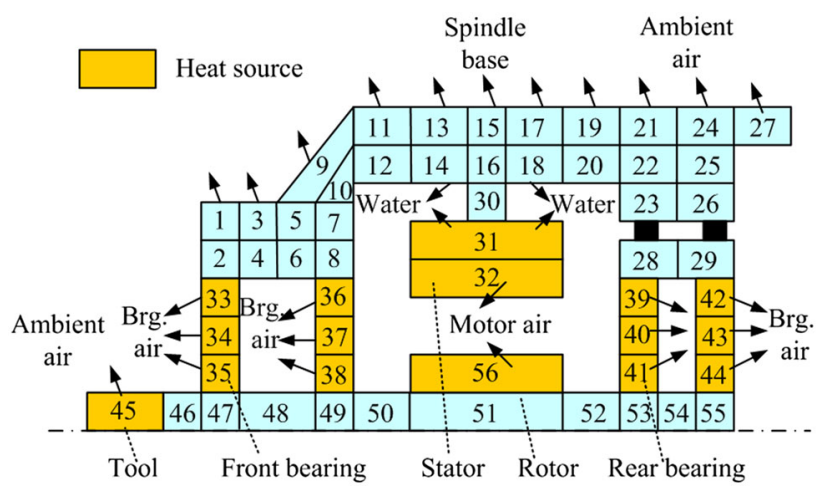

Figure 3 Finite element spindle model marked with the heat sources and sinks [37]

detail. More research about the thermal resistance network of the bearing assembly can be found in Refs. [38, 39].

As the real structure of a spindle box is complicated, the finite difference method (FDM) and FEM are often preferred to obtain accurate results. Jedrzejewski, et al. [40], set up a thermal analysis model of a high precision CNC machining center spindle box using a combination of the FEM and the FDM. Refs. [41, 42] created an axially symmetric model for a single shaft system with one pair of bearings using the FEM to estimate the temperature distribution of the whole spindle system.

\subsection{Heat Generated in the Feed Screw Nuts}

The thermal deformation of the feed screw nuts effects the linear position error of heavy-duty machine tools. The axial thermal errors become bigger as the runtime of the feed system increases. However, after running for a period of time, the feed system approaches the thermal balance and reaches the approximation steady state, and the variations of thermal errors ease. The variation of radial thermal expansion of the feed screw nuts is so minor that it may be ignored [43]. In the ball screw system, the heat generation sources are the nuts and 2 bearings, and the heat loss sources are liquid cooling and surface convection (shown in Figure 4) [44, 45]. The thermal balance equation can be expressed by

$Q_{\mathrm{b} 1}+Q_{\mathrm{b} 2}+Q_{\mathrm{n}}-Q_{\mathrm{sc}}-Q_{\mathrm{c}}=\rho c V \frac{\partial T}{\partial t}$,

where $Q_{\mathrm{b} 1}$ and $Q_{\mathrm{b} 2}$ are the conduction heat from the 2 support bearings, $Q_{\mathrm{n}}$ is the conduction heat from the nut, $Q_{\mathrm{sc}}$ is the convection heat from rotation of the ball screw shaft, and $Q_{\mathrm{c}}$ is the convection heat lost from the cooling liquid. The material density is noted as $\rho, c$ is the specific heat, $V$ is the volume, $T$ is the temperature, and $t$ is the time. 


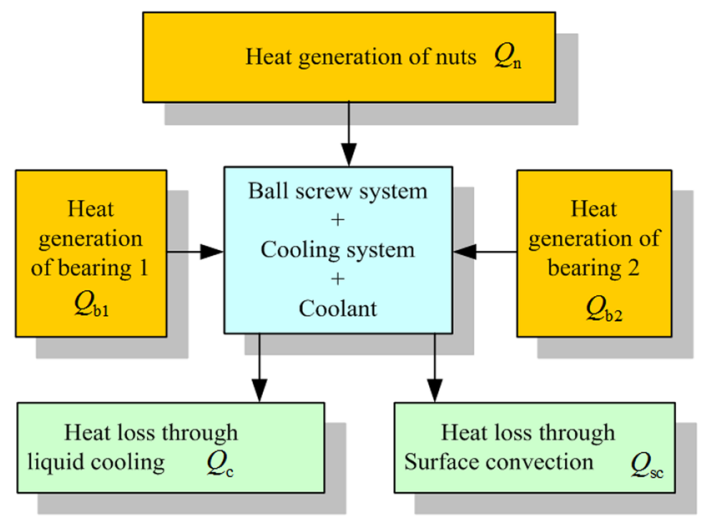

Figure 4 Schematic diagram of the screw nuts thermal model

The conduction heat from the 2 support bearings, $Q_{\mathrm{b} 1}$ and $Q_{\mathrm{b} 2}$ can be caculated as shown in section 2.2. The conduction heat from the nut $Q_{\mathrm{sc}}$ can be defined as below:

$Q_{\mathrm{sc}}=0.12 \pi f_{0 \mathrm{n}} v_{0 \mathrm{n}} n_{\mathrm{n}} M_{\mathrm{n}}$,

where $f_{0 \mathrm{n}}$ is a factor related to the nut type and method of lubrication, $v_{0 n}$ is the kinematic viscosity of the lubricant, $n_{\mathrm{n}}$ is the screw rotation velocity, and $M_{\mathrm{n}}$ is the total frictional torque of the nut (preload and dynamic load) [44].

Mayr, et al. [46], established the equivalent thermal network model of the ball screw with an analytical method. $\mathrm{Xu}$, et al. [44, 47], discovered that, in the case of a large stroke, the heat produced by the moving nut was dispersed on a larger scale than in other cases, so the screw cooling method has better deformation performance than the nut cooling method. Conversely, in the case of a small stroke, the thermal deformation performance of the nut cooling method is better than that of the screw cooling method. Some researchers [4, 48, 49] developed the FEM model for the screw, in which the strength of the heat source measured by the temperature sensors was applied to the FEM model to calculate the thermal errors of the feed drive system. Jin, et al. [50-52], presented an analytical method to calculate the heat generation rate of a ball bearing in the ball screw/nut system with respect to the rotational speed and load applied to the feed system.

\subsection{Environmental Temperature Effects}

Environmental temperature fluctuation changes the temperature of the heavy-duty CNC machine tool globally, and affects its machining accuracy greater compared with the small and medium-sized machine tools [1]. Environmental temperature fluctuations have daily periodicity and seasonal periodicity simultaneously. Tan, et al. [53], decomposed the environmental temperature fluctuations into Fourier series form (shown in Figure 5). $x$ represents time in minutes. The basic angular frequency is $\omega_{0}=2 \pi / T_{0}$, where $T_{0}=1440 \mathrm{~min} . A_{0}$ is the average value of the daily cycle temperature that the current temperature belongs to, and it can be obtained from the temperature history through time series analysis. $A_{n}$ represents the amplitude of the temperature fluctuation for each order, and the orders are multiples of the basic frequency $\omega_{0} . \phi_{n}$ is the initial phase of each order. Tan, et al's experiment verifies that the environmental temperature has a significant impact on the thermal error of the heavy-duty CNC machine tool, and there exists hysteresis time between the environmental temperature and the corresponding thermal deformation that changes with climate and seasonal weather.

Zhang, et al. [54], established the thermal error transfer function of each object of the machine tool based on the heat transfer mechanism. Then, based on the assembly dimension chain principle, the thermal error transfer function of the whole machine tool was obtained. As the thermal error transfer function can be deduced using Laplace transform, the thermal error characteristic of the machine tool can be studied with both time domain and frequency domain methods. Taking the environmental temperature fluctuations as input, based on the thermal error transfer function, the environmental temperature induced thermal error can be obtained.

\subsection{Thermal Analysis of the Global Machine Tool}

The heat generated in the spindle and feed screw nuts is discussed in Sections 2.1 and 2.2. The global thermal deformation of heavy-duty machine tools is influenced by varieties of heat sources as noted at the beginning of Section 2. The FEM was utilized for the thermal analysis of the global machine tool. Mian, et al. [55], presented a novel offline technique using finite element analysis (FEA) to simulate the effects of the major internal heat sources, such as bearings, motors and belt drives, and the effects of the ambient temperature variation during the machine's operation. For this FEA model, the thermal boundary conditions were tested using 71 temperature sensors. To ensure the accuracy of the results, experiments were conducted to obtain the thermal contact conductance values. Mian, et al. [56], further studied the influence of the ambiance temperature variation on the deformation of the machine tool using FEM. The validation work was carried out over a period of more than a year to establish the robustness to the seasonal changes and daily changes in order to improve the accuracy of the thermal simulation of machine tools. Zhang, et al. [57], proposed a whole-machine temperature field and thermal deformation modeling with a simulation method for vertical machining centers. Mayr, et al. [58-60], combined the advantages of FDM and FEA to simulate the thermo-mechanical behavior of machine tools (shown in Figure 6). 
Figure 5 Time-frequency characteristics of environmental temperature [53]

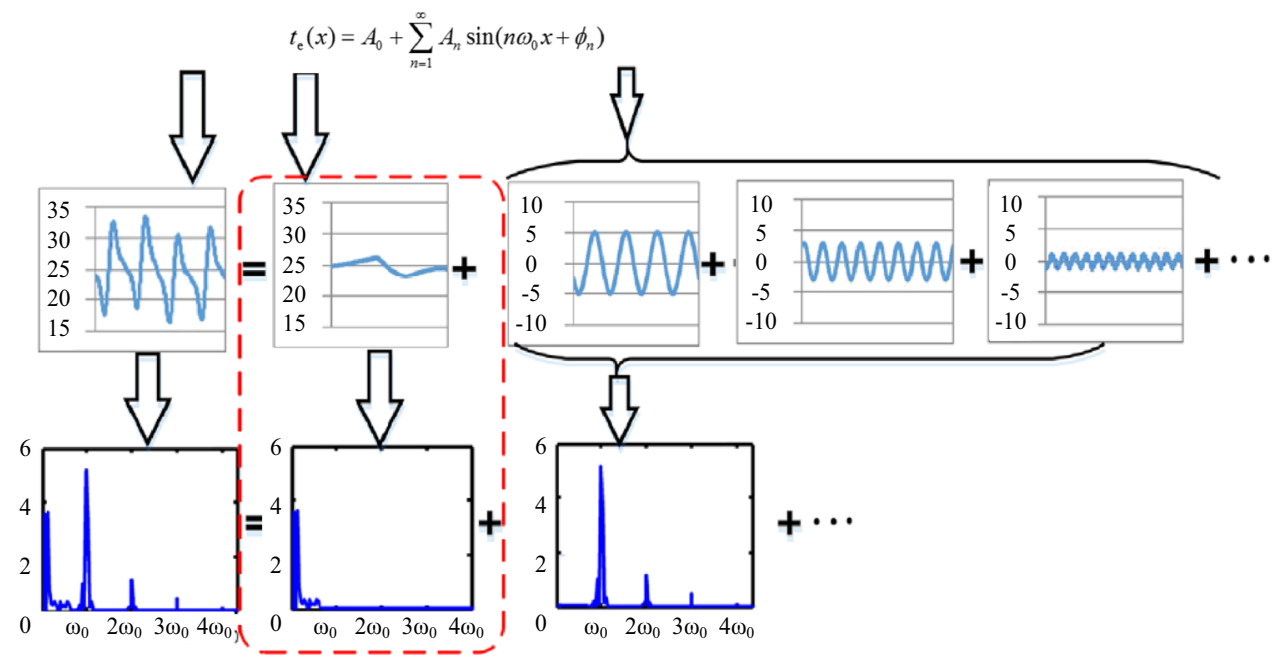

FDEM- a serial simulation-tool

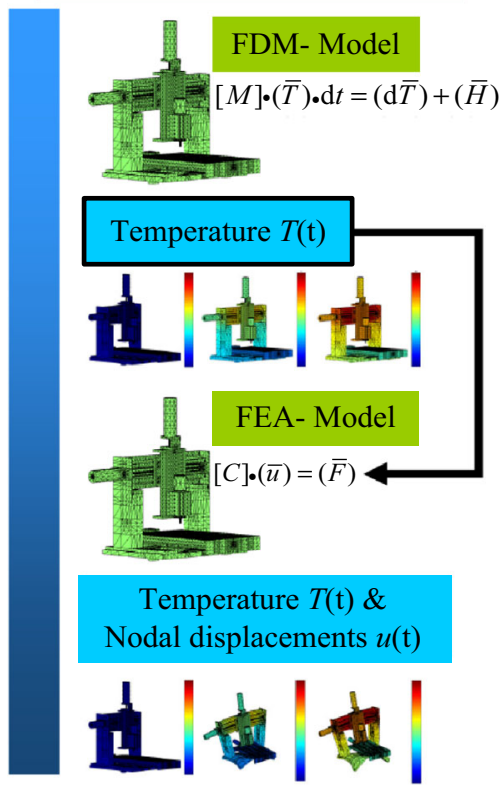

Figure 6 Schematic of the FDEM [58]

The transient 3-D temperature distribution at discrete points of time during the simulated period was calculated using the FDM. Those were then used as temperature field for the FEM to calculate the thermally induced deformations.

\section{Temperature Field Monitoring Technology for Heavy-Duty CNC Machine Tools}

The formation process of thermal errors in heavy-duty CNC machine tools occurs in the following steps: heat sources $\rightarrow$ temperature field $\rightarrow$ thermal deformation field $\rightarrow$ thermal error. It is obvious that the relationship between the thermal deformation field and thermal error is more relevant than the relationship between the temperature field and thermal error. However, it is quite difficult to measure the micro-thermal-deformation of the whole machine structure directly and the surface temperature of the machine tool is easier to obtain inversely. Existing thermal error prediction models are mostly based on the temperature measurement from the surface of the machine tool, establishing the relationship between the thermal drift of the cutting tool tip and the temperature at critical measuring point. Therefore, the temperature monitoring of the machine tool is a key technology in the thermal error research of CNC machine tools. It can be divided into the contact-type temperature measurements and non-contact temperature measurements, according to the installation form of the temperature sensor.

\subsection{Contact-Type Temperature Measurement of Heavy-Duty CNC Machine Tools}

The contact-type surface temperature measurement sensors used in the temperature monitoring of CNC machine tools are mainly thermocouples and platinum resistance temperature detector (RTD). Their installation can be divided into the paste-type, pad-type, and screw-type. Thermocouples and platinum resistance temperature detectors are mostly used for discrete surface temperature measurement. Heavy-duty CNC machine tools have a large volume and decentralized internal heat sources.

Delbressine, et al. [61], realized that it was difficult to determine the locations and qualities of the temperature sensors, so numerous temperature sensors should be arranged on the surface of the machine tools. Mian, et al. [55], used 65 temperature sensors to measure the detailed temperature gradient caused by the internal heat sources, and applied them to FEM. Zhang, et al. [57], used 32 
platinum resistance temperature sensors to establish a machine tool temperature field. In 2014, Tan, et al. [53], installed 33 temperature sensors on the heavy-duty gantry type machine tool XK2650 (shown in Figure 7), and established a thermal error prediction model considered the influence of the environmental temperature. This model can predict $85 \%$ of the thermal error and has a good robustness. In addition, Refs. [62-68] used the thermal resistance to measure the machine tool surface temperature, and Refs. [69, 70] used the thermocouples. Werschmoeller and $\mathrm{Li}$ [71] embedded 10 mini flaky thermocouples into the cutting tool to monitor the cutting tool temperature field. Liu, et al. [72], embedded thermocouples into the workpiece to investigate the workpiece temperature variations that resulted from helical milling.

These electrical temperature-sensing technologies mainly utilize the linear relationship between the values of the potential, resistance, or other electrical parameters of the sensing materials and temperature to detect the temperature. They have a simple structure, fast response capability, high sensitivity, and good stability. So they play an important role in the thermal error experimental research of heavy-duty $\mathrm{CNC}$ machine tools. However, there are some common flaws in the electrical temperature measurement sensors. These include the following:

\section{(1) Poor environmental adaptability}

Many parts of the heavy-duty CNC machine tools are in environments exposed to oil, metal cutting chip dust, and coolant. The wires and sensitive components of electrical

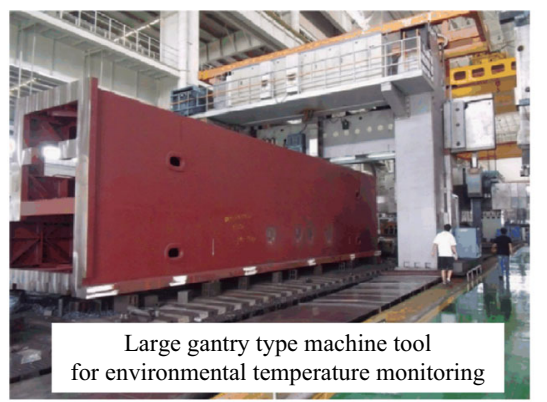

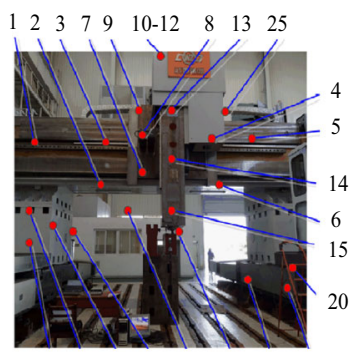

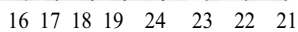

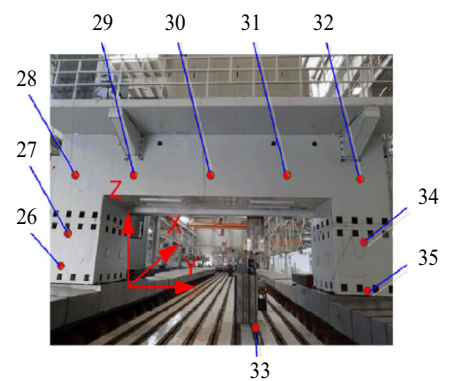

33
Figure 7 Temperature monitoring of the heavy-duty gantry type machine tool XK2650 [53] temperature sensors are all made from metal materials, which are susceptible to corrosion and damage, and have a short working life in a relatively harsh environment.

(2) Weak ability to resist electromagnetic interference

Heavy-duty CNC machine tools have many inductance elements, like the motors and electric control cabinet, which form strong time-varying electromagnetic fields. The testing signals of electrical temperature sensors are easily interfered with electromagnetic fields during transmission, reducing the signal-to-noise ratio (SNR), accuracy and reliability of the test data.

\section{(3) Wide variety of signal transmission wires}

The principle of electrical temperature sensors is that of an electrically closed circuit. A single electrical temperature sensor has two conductor wires, and a plurality of electrical sensors cannot be connected in a series connection. If there are $N$ electrical sensors, there are $2 N$ wires. So it is difficult to create the layout of large amounts of wires in heavy-duty CNC machine tools.

The testing results for the above electrical temperature sensors show the discrete-point temperature of the heavyduty CNC machine tool's surface. The whole temperature field can be reconstructed by using the FDM. Due to the use of few discrete temperature points, it is difficult to establish an accurate integral temperature field of a heavyduty CNC machine tool, particularly to calculate its internal temperature. Currently, prediction models such as multiple regression or neural networks, are all established based on discrete temperature points, so there is little research on the integral temperature field reconstruction of heavy-duty CNC machine tools. However, it is of great significance for the study of the thermal error mechanism to obtain the 3-D temperature field of CNC machine tools.

\subsection{Non-Contact Type Temperature Measurement of Heavy-Duty CNC Machine Tools}

Currently, infrared thermal imaging technology is a noncontact type temperature measurement method that is often applied to thermal error study of heavy-duty CNC machine tools, and it is part of the radiation temperature measurement method.

A thermal infrared imager gathers infrared radiant energy and delivered it to an infrared detector through the optical system, in order to process the infrared thermal image. Using the thermal infrared imager test results, one can select the key temperature points to establish a thermal error model. Qiu, et al. [73], measured the spindle box temperature field through FLIR thermal imager, and selected 18 temperature points symmetrically to establish the model of the spindle thermal components using the 
multiple linear regression method. Infrared thermal imaging is suitable for the study of the thermal characteristics of key parts of the heavy-duty $\mathrm{CNC}$ machine tools as it visualizes the global temperature field of the surface with a high temperature resolution.

$\mathrm{Wu}$, et al. [74], researched the thermal behaviors of the support bearing (shown in Figure 8) and screw nut of the ball screws (shown in Figure 9) by using infrared thermographs. Uhlmann and $\mathrm{Hu}$ [75], captured the temperature field when the spindle running was at $15000 \mathrm{r} / \mathrm{min}$ for 150 min, and compared their data with emulational temperature fields (shown in Figure 10). Xu, et al. [47], examined the heat generation and conduction of the ball screws and investigated how the different cooling methods affects the temperature distribution using infrared thermal imaging technology. Zhang, et al. [76], studied temperature variable optimization for precision machine tool thermal error compensation using infrared thermometer.

The infrared thermal imager can visualize the temperature distribution of $\mathrm{CNC}$ machine tools, and plays an important role in thermal error study of CNC machine tools. However, the infrared thermal imager is a two-dimensional plane imaging infrared system. One infrared thermal imager cannot measure the overall global temperature field of heavy-duty CNC machine tools. Even with the use of multiple expensive infrared cameras for measuring the global temperature field of heavy-duty $\mathrm{CNC}$ machine tools, it is still difficult to track the temperature field of the moving parts when heavy-duty CNC machine tools are involved in actual processing.

The shortcomings mentioned in Section 3.1 and Section 3.2 limit the electrical temperature sensors and infrared sensing technology for monitoring the real-time temperature over the long-term in heavy-duty $\mathrm{CNC}$ machine tools. There must be some breakthroughs in the temperature field measurement of heavy-duty $\mathrm{CNC}$ machine tools in order to develop a highly intelligent temperature measurement and thermal error compensation system that is suitable for heavy-duty CNC machine tools for commercialization.

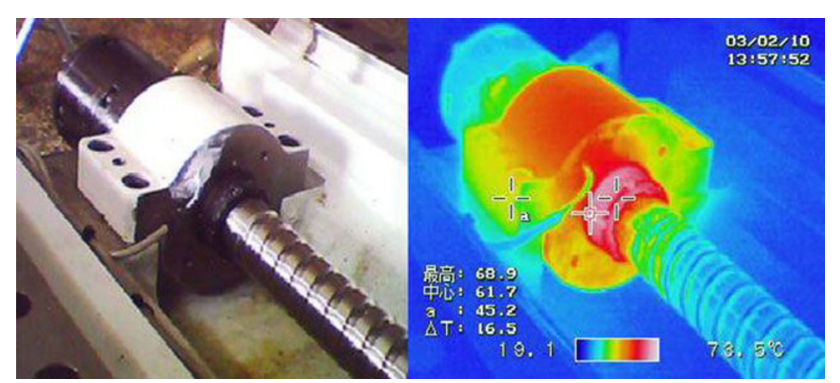

Figure 8 Thermal imaging of the screw support bearings [74]

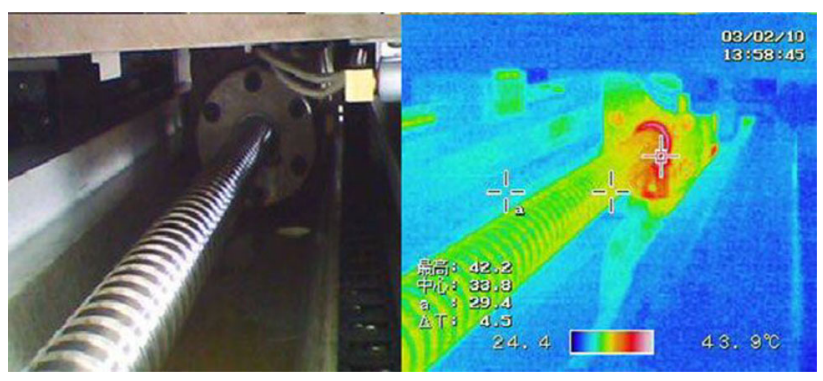

Figure 9 Thermal imaging of the screw nut [74]

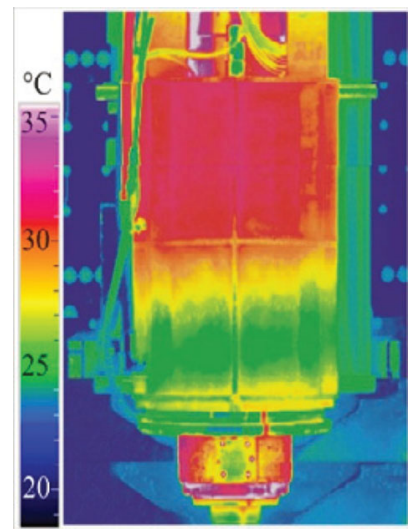

Figure 10 Thermal imaging of the headstock temperature field [75]

\section{Thermal Deformation Monitoring Technology for Heavy-Duty CNC Machine Tools}

\subsection{Thermal Error Monitoring of the Cutting Tool Tip}

For the thermal error detecting of the cutting tool tip, three categories of sensors are mainly used, that are non-contact displacement detection sensors, high precision double ball gauge, and laser interferometer. The non-contact displacement detection sensors utilized in machine tools include eddy current transducers, capacitive transducers and laser displacement sensors. Though their sensing principles are different, their installation and error detection method are consistent with each other. The high precision double ball gauge and laser interferometer are mainly used to detect the dynamic geometric error of the machine tool, and they can also be competent at thermal error detecting.

\subsubsection{Five-Point Detection Method}

The five-point detection method (shown in Figure 11) is only applicable to monitoring the thermal error of a machine tool when the spindle box is not moving. It detects the thermal deformation caused by the ambient temperature or by the rotation of the spindle in ISO230-3. This method 
measures the three position errors $\delta_{\mathrm{p} x}, \delta_{\mathrm{p} y}$, and $\delta_{\mathrm{p} z}$ in the $X$, $Y$, and $Z$ direction and two angle errors $\varepsilon_{\mathrm{p} x}$ and $\varepsilon_{\mathrm{p} y}$ rotating around the $X$ and $Y$ axes of the tool cutting tip. Their values can be calculated by Eq. (8):

$$
\left\{\begin{array}{l}
\delta_{\mathrm{p} x}=\delta_{x 1}+L \times \varepsilon_{\mathrm{p} x}, \\
\delta_{\mathrm{p} y}=\delta_{y 1}+L \times \varepsilon_{\mathrm{p} y}, \\
\delta_{\mathrm{pz}}=\delta_{z}, \\
\varepsilon_{\mathrm{p} x}=\left(\delta_{y 1}-\delta_{y 2}\right) / d, \\
\varepsilon_{\mathrm{p} y}=\left(\delta_{x 1}-\delta_{x 2}\right) / d,
\end{array}\right.
$$

where $\delta_{x 1}, \delta_{x 2}, \delta_{y 1}, \delta_{y 2}$, and $\delta_{z}$ are the displacements detected by the displacement sensors $S_{X 1}, S_{X 2}, S_{Y 1}, S_{Y 2}$, and $S_{Z} . d$ is the sensor distance between sensor $S_{X 1}$ and sensor $S_{X 2}$, and $L$ represents the effective length of the test mandrel that is often made by steel, or invar alloy to oatain higher testing precision.

As the test mandrel is a cylinder, a shift in one direction will cause a test error in the other direction. Using $\delta_{x 1}$ and $\delta_{y 1}$ for an example (shown in Figure 12), when the cutting tool tip moves from point $O$ to point $O$ ' in the $X O Y$ plane, the real position errors are $\delta_{x 1}$ and $\delta_{y 1}$. However, the position errors detected by the displacement sensors are $\delta^{\prime}{ }_{x 1}$ and $\delta^{\prime}{ }_{y 1}$, correspondingly. The relationship between them can be expressed by Eq. (9):

$\left\{\begin{array}{l}\delta_{x 1}^{2}+\left(R-\delta_{y 1}^{\prime}+\delta_{y 1}\right)^{2}=R^{2}, \\ \delta_{y 1}^{2}+\left(R-\delta_{x 1}^{\prime}+\delta_{x 1}\right)^{2}=R^{2},\end{array}\right.$

where $R$ represents the radius of the test mandrel. The real position errors $\delta_{x 1}$ and $\delta_{y 1}$ can be expressed by the displacement sensors's detected data. It has to be noted that $\delta_{\mathrm{p} x}, \delta_{\mathrm{p} y}, \delta_{\mathrm{p} z}, \varepsilon_{\mathrm{p} x}$, and $\varepsilon_{\mathrm{p} y}$ interact with each other, and Eq. (9) does not consider $\varepsilon_{\mathrm{p} x}$ and $\varepsilon_{\mathrm{p} y}$.

\subsubsection{High Precision Double Ball Gauge Method}

A double ball gauge consists of two precision metal spheres and a telescoping bar installed on a grating ruler
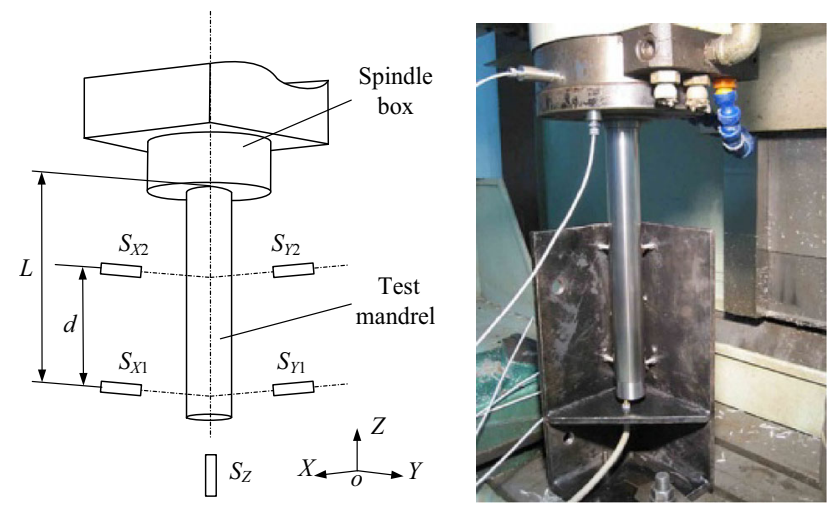

Figure 11 Five-point detection method

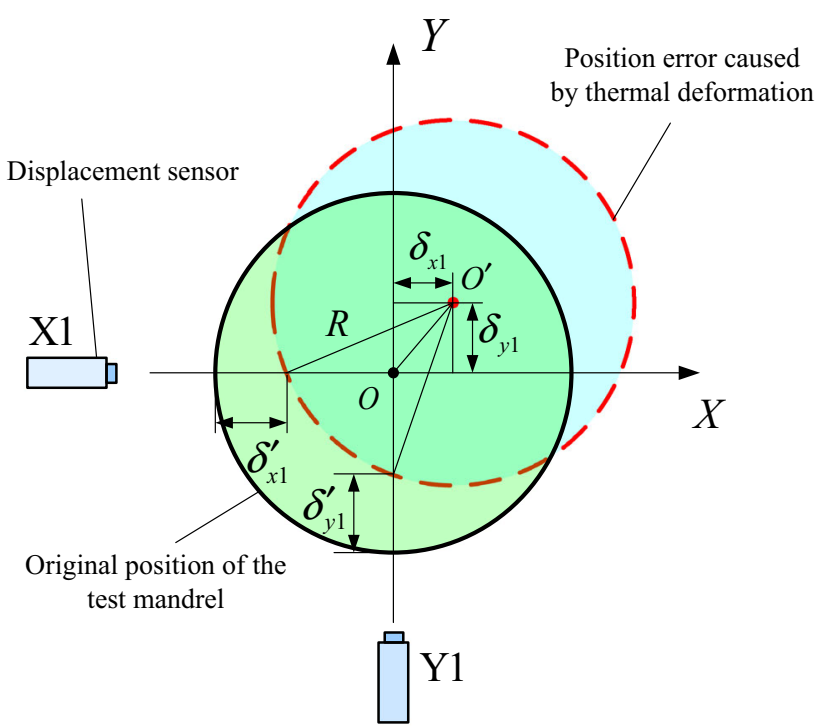

Figure 12 Test error of five-point detection method

that can detect the displacement (shown in Figure 13). The double ball gauge method is recommended in the ASME B5.54 [77] to detect comprehensive error in machine tools. The advantage of this method is that it can detect the tool tip trajectory error caused by the geometric error and thermal deformation. However, the heat expansion and bending deformation of the telescoping bar or a small displacement of the stand affect the test accuracy of this method.

\subsubsection{Laser Measurement Method}

The laser interferometer instrument utilizes the Doppler effect caused by the frequency shift to detect the machine tool's linear position error (shown in Figure 14) and angle error (shown in Figure 15) moving along the guide [78]. A dual frequency laser interferometer is a heterodyne interferometer based on single frequency laser interferometers. It has a large gain and high SNR and it is especially suitable for measuring the thermal error of heavy-duty CNC machine tools. The laser measurement methods are widely
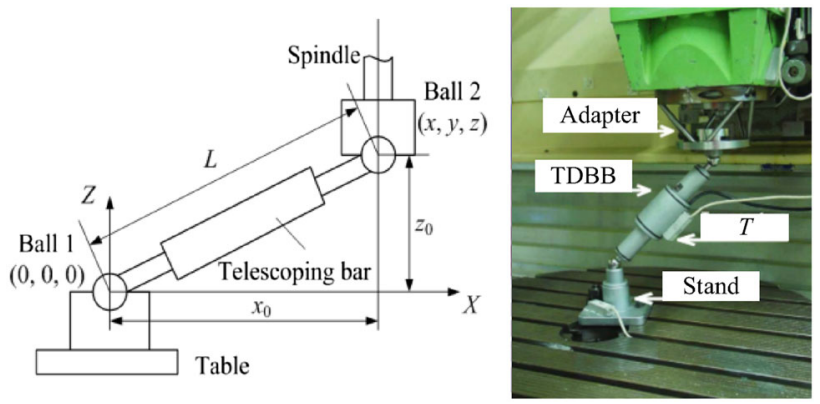

Figure 13 Double ball gauge method 
used for geometric accuracy calibration and the heat-induced position error, angle error and straightness error of heavy-duty CNC machine tools. Ruiz, et al. [79], designed a set of optical measuring systems based on the laser interference principle to track and locate the tool tip of the machine tool.

\subsection{Thermal Deformation Monitoring of Large Structural Parts of the Machine Tool}

Currently, the displacement detection apparatus, which detects the deformation of large structural parts of heavyduty CNC machine tools is based on the laser displacement sensors, eddy current sensors, and capacitive sensors. For instance, Gomez-Acedo, et al. [80], utilized the inductive sensors array to measure the thermal deformation of a large gantry-type machine tools(shown in Figure 16). Additionally, the laser interferometer with different accessories can measure a range of values, including the precision position, straightness, verticality, yaw angle, parallelism, flatness, and turntable accuracy, and it plays an important role in the detection of the thermal deformation of a heavy-duty $\mathrm{CNC}$ machine tool. However, since some of these instruments mentioned above are very large, or in demanding environments, or have small measurement range, it is difficult to engage in the long-term monitoring of heavy-duty CNC machine tools. The direct measurement method requires the installation of displacement sensors on a fixed base as a benchmark, but for CNC machine tools, especially heavyduty $\mathrm{CNC}$ machine tools, it is difficult to find a large constant benchmark (any large base will incur thermal deformation or force-induced deformation, both of which affect the measurement accuracy). It is difficult for the direct displacement measurement method to completely reconstruct the real-time deformation of heavy-duty $\mathrm{CNC}$ machine tools. Therefore, researchers are trying to find a more reliable and practical measuring principal and method to monitor the deformation of heavy-duty $\mathrm{CNC}$ machine tool structures using laser interferometer [81].

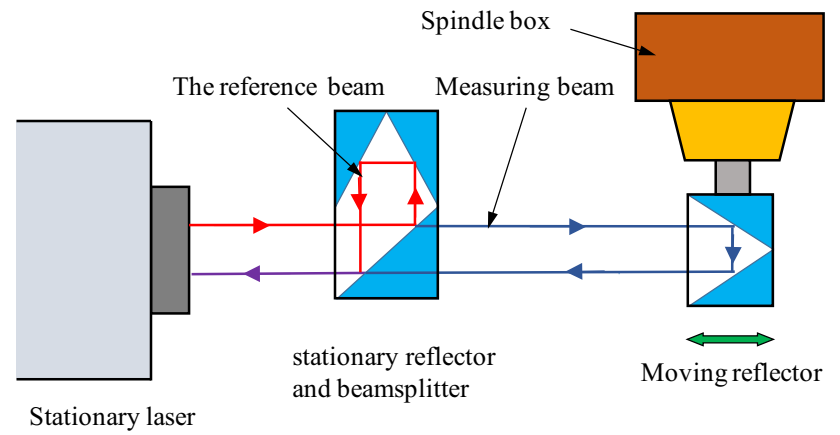

Figure 14 Tool tip's linear position error measurement

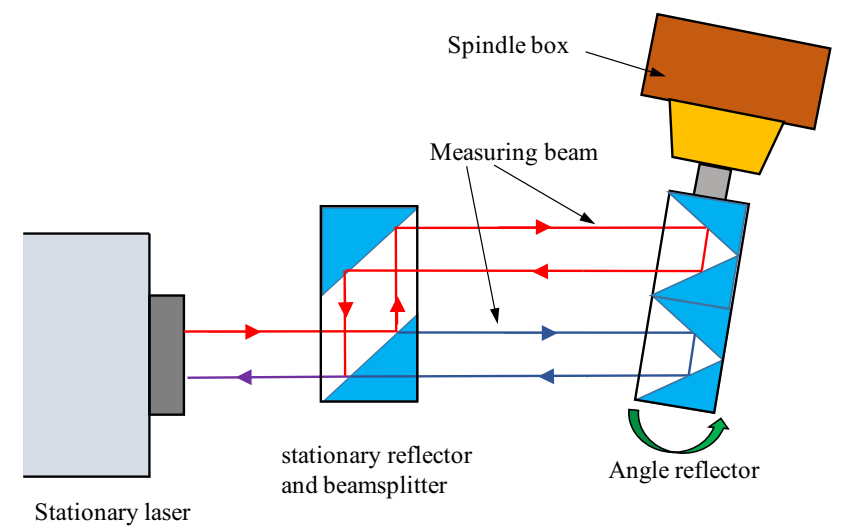

Figure 15 Tool tip's angle error measurement

\section{Application of FBG Sensors in Heavy-Duty CNC Machine Tools}

\subsection{Principle and Characteristics of Fiber Bragg Grating Sensors}

A fiber Bragg grating sensor is a type of optical sensitive sensor that has been utilized and studied for nearly forty years. A fiber Bragg grating sensor has a number of unparalleled characteristics. It is small and explosionproof, has electrical insulation, and is immune to electromagnetic interference. It offers high precision, and high reliability. Multiple FBG sensors can be arranged in one single fiber. Therefore, it has been widely used in many engineering fields and mechanical system [82].

The sensing principle of a FBG is fundamentally based on a periodic perturbation of the refractive index along the fiber axis formed by exposing the fiber core to the illumination of an intense ultraviolet interference pattern. When a broad-band light propagates along the optical fiber to a grating, a single wavelength is reflected back while therest of the signal is transmitted with a small attenuation (shown in Figure 17). The reflected wavelength is the Bragg wavelength and it can be expressed by the following equation:

$\lambda_{\mathrm{B}}=2 n_{\mathrm{eff}} \Lambda$,

where $\lambda_{\mathrm{B}}$ is the Bragg wavelength, $n_{\text {eff }}$ is the effective refractive index of the fiber core, and $\Lambda$ is the grating period. A FBG shows great sensitivity to various external perturbations, especially strain and temperature. Any change of stain or temperature will cause the change of $n_{\text {eff }}$ or $\Lambda$, and lead to the shift of $\lambda_{\mathrm{B}}$. Hence, by monitoring the Bragg wavelength shift, the value of the strain or temperature is determined.

The wavelength variation response to the axial strain change $\Delta \varepsilon$ and temperature change $\Delta T$ is given by: 
Figure 16 Thermal deformation detection of a heavy-duty CNC machine tool based on the inductive sensors array [80]
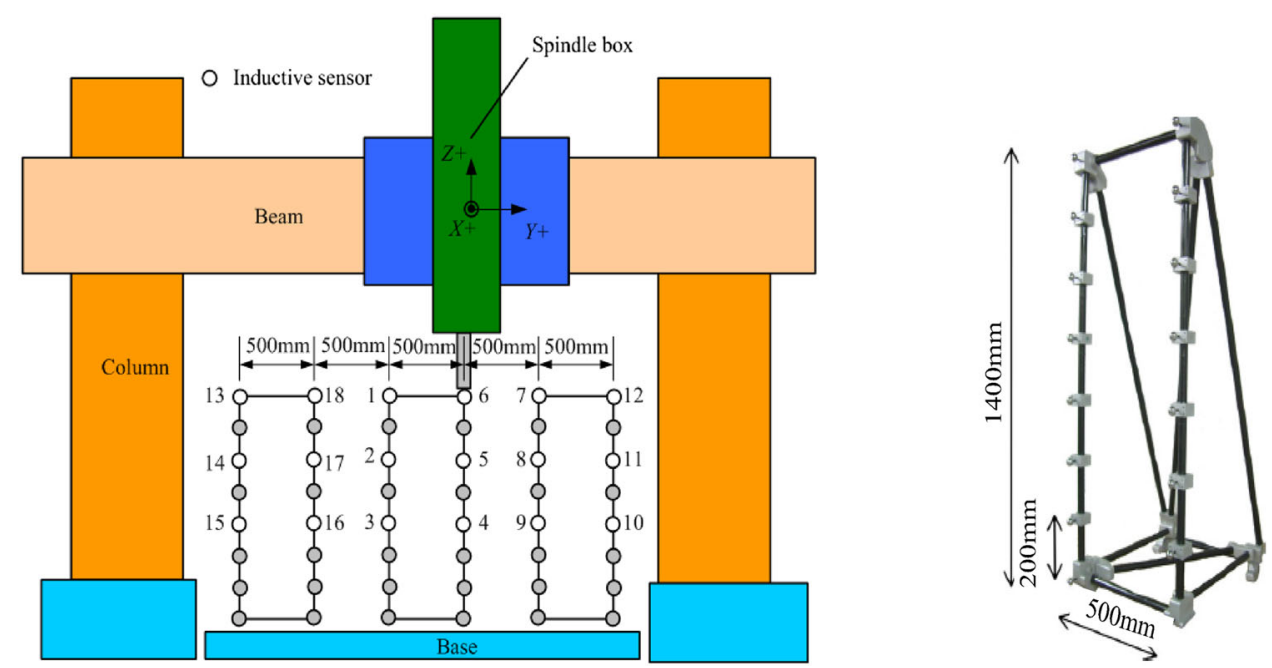

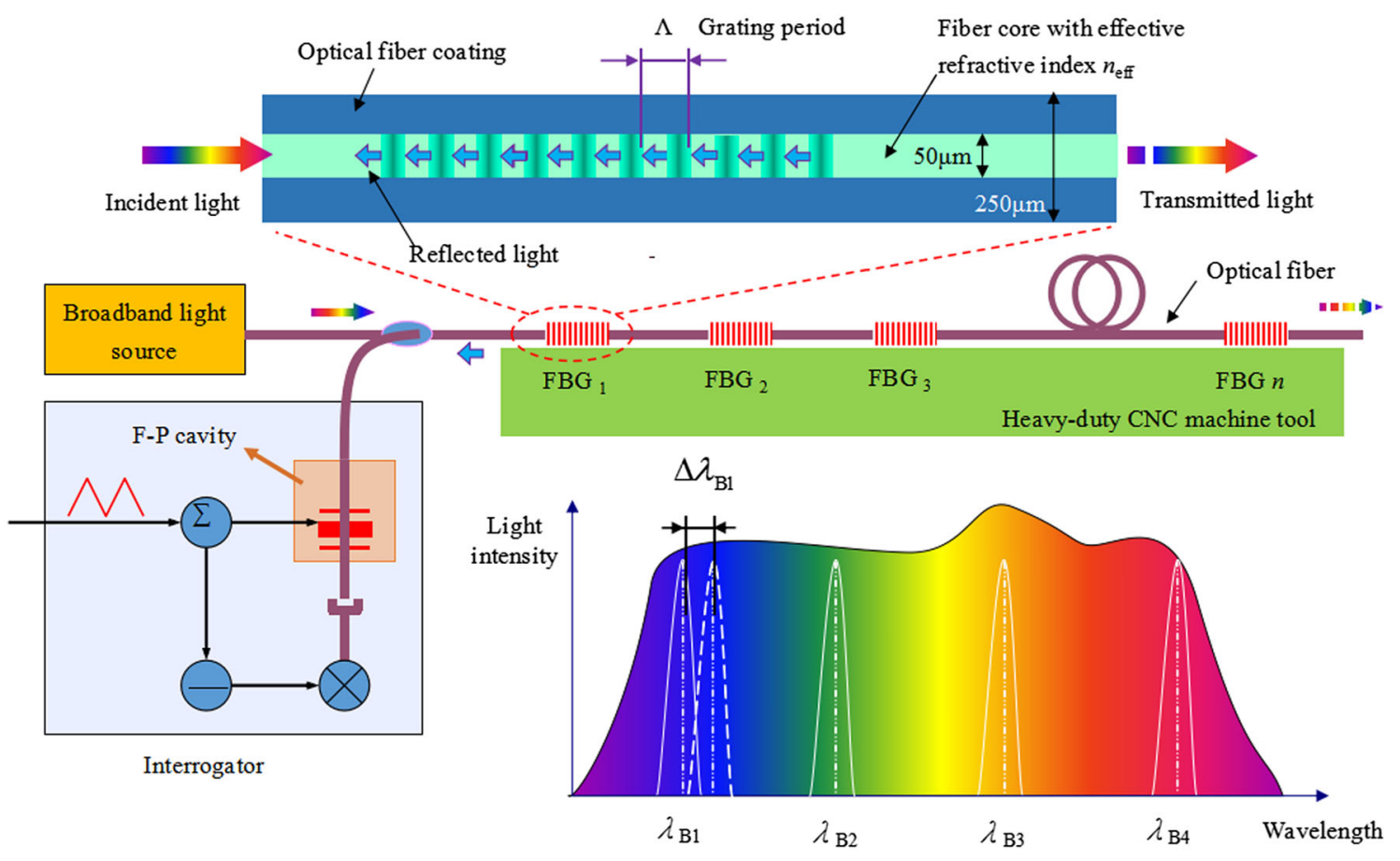

Figure 17 Distributed detection principle of the fiber Bragg grating sensors

$\frac{\Delta \lambda_{\mathrm{B}}}{\lambda_{\mathrm{B}}}=\left(1-p_{\mathrm{e}}\right) \Delta \varepsilon+\left(\alpha_{\mathrm{f}}+\zeta\right) \Delta T$,

where $p_{\mathrm{e}}, \alpha_{\mathrm{f}}$, and $\zeta$ are, respectively, the effective photoelastic coefficient, thermal expansion coefficient, and thermal-optic coefficient of the fused silica fiber.

In the literatures, there is little application of fiber grating sensors in the manufacturing industry and almost nothing concerning the machine tool temperature detection and thermal error monitoring. The detection technology based on fiber Bragg grating sensing is especially suitable for the thermal error monitoring of heavy-duty $\mathrm{CNC}$ machine tools. It offers a number of advantages over traditional detection technologies, as shown follows:

(1) A fiber Bragg grating sensor has a small volume, light weight, and high measurement precision. It is especially unparalleled when a series of FBG sensors that detect a variety of physical parameters distribute in a single fiber. It is suitable for heavy-duty CNC machine tool's large volume, multiple heat sources, and complex structure.

(2) A fiber Bragg grating sensor is highly resistant to corrosion, and high temperature. It is especially 
suitable for the processing under conditions of high temperature, high humidity, excessive vibration, dust, and other harsh environment. It meets the requirements of the long-term stability and reliability for machine tool detection.

(3) A fiber Bragg grating sensor has electrical insulation, and is immune to electromagnetic interference (EMI), making it suitable for harsh processing conditions of the heavy-duty CNC machine tool. It can achieve accurate measurement of the thermal error of machine tools.

\subsection{Temperature Field Monitoring of Heavy-Duty CNC Machine Tool Based on Fiber Bragg Grating Sensors}

\subsubsection{Fiber Bragg Grating Temperature Sensors for the Surface Temperature Measurement of Machine Tools}

The fiber Bragg grating temperature measurement technology has become more mature, but the research in this field is mainly concentrated on the extremely high or low temperature measurement and the temperature sensitive enhancing technology. Currently, fiber Bragg grating temperature sensors can be divided into 5 parts by the form of packaging: tube-type fiber Bragg grating temperature sensor [83, 84], substrate-type fiber Bragg grating temperature sensor [85, 86], polymer packaged fiber Bragg grating temperature sensor [87], metalcoated fiber Bragg grating temperature sensor [88-93], and sensitization-type fiber Bragg grating temperature sensor [94].

In order to easily install the temperature sensor and not destroy the internal structure of the machine tools, the temperature of the surface of the machine tools is usually tested and used as the basic data for the thermal error compensation. Measuring the surface temperature accurately in the high gradient temperature field is an challenging technical problem. In the present study, the traditional electrometric method for measuring the temperature of the surface of the machine tool rarely considers the precision problem of measurement. Fiber Bragg grating has been widely used in the field of temperature measurement, but there is little research on the measurement error of the surface temperature measurement. The machine tool surface temperature measurement error can be divided into 3 parts:

(1) When the temperature sensor's surface makes contact with the machine tool, the heat flow will be more concentrated at the testing point. It results in temperature measurement error $\Delta T_{1}$.
(2) The thermal contact resistance between a temperature sensor's surface and machine tool surface results in a temperature drop $\Delta T_{2}$.

(3) There is a certain distance between the temperature sensor's sensing point and the surface of the machine tool, which creates the temperature measurement error $\Delta T_{3}$.

Optical fibers are mainly made of quartz and organic resin material. Their thermal conductivity is less than the metal material wire of the thermocouple and thermal resistance. The first temperature measurement error $\Delta T_{1}$ of the fiber Bragg grating is significantly smaller than that of the latter two, and the main error factors are the thermal contact resistance and the distance of the temperature sensing point. A high gradient temperature field model of the heating surface is established by the FEM [95]. In this model, when the hot surface temperature and the air temperature are $90.2{ }^{\circ} \mathrm{C}$ and $22{ }^{\circ} \mathrm{C}$, the temperature falling gradient near the hot surface is $-46.4^{\circ} \mathrm{C} / \mathrm{mm}$ (shown in Figure 18).

Due to the existence of the coating layer on the surface of the fiber Bragg grating sensor, there is about a $0.15 \mathrm{~mm}$ gap between the machine tool surface and the fiber Bragg grating temperature sensing point. In the temperature gradient of $-46.4{ }^{\circ} \mathrm{C} / \mathrm{mm}$, the small space is sufficient to produce a large temperature test error. By using thermal conductive paste, the uniformity of the surface temperature can be improved, and the error of the surface temperature measurement by FBG can be significantly reduced compared to that from a commercial thermal resistance surface temperature sensor. Ref. [96] studied influence of the installation types on surface temperature measurement by a FBG sensor. The surface

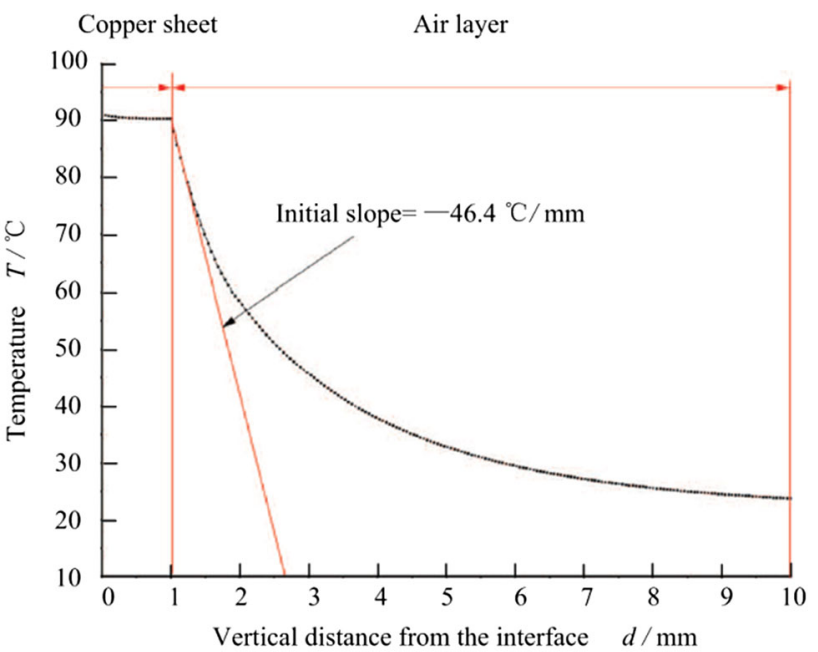

Figure 18 Temperature gradient distribution of surface temperature measurement [95] 
temperature measurement error of the FBG sensor with single-ended fixation, double-ended fixation and fullyadhered fixation are theoretical analyzed and experimental studied. The single-ended fixation results in a positive linear error with increasing surface temperature, while the double-ended fixation and fully-adhered fixation both result in non-linear error with increasing surface temperature that are affected by thermal expansion strain of the tested surface's material. Due to its linear error and strain-resistant characteristics, the single-ended fixation will play an important role in the FBG surface temperature sensor encapsulation design field .

\subsubsection{Temperature Measurement of the Machine Tool Spindle Bearing Based on the Fiber Bragg Grating} Sensors

The spindle is the core component with complex assembly mechanical structure in heavy-duty $\mathrm{CNC}$ machine tool. The spindle consists of the rotating shaft, the front and rear bearings, and the spindle base. For the motorized spindle, it also includes the rotor and stator. As the structure of the spindle is very compact and narrow, to fix the temperature sensor inside the spindle is difficult. The thermogenesis of spindle's front bearings is a research hotspot that has great influence to the thermal error of the heavy-duty CNC machine tool.

Liu, et al. [97], installed two FBG temperature sensors (position 1 and 3) and four thermal resistors (position 1, 2, 3 , and 4) on the bearing support surface of the spindle (shown in Figure 19). With the shaft rotating freely, the temperature rise amplitudes in position 1, 2, 3, and 4 are consistent with each other. The measured temperature by the FBG temperature sensors and the thermal resistors are the same. As the volume of the FBG temperature sensor is rather smaller than the commercial thermal resistors and thermocouples, it has natural advantages to measure the internal temperature of the spindle.

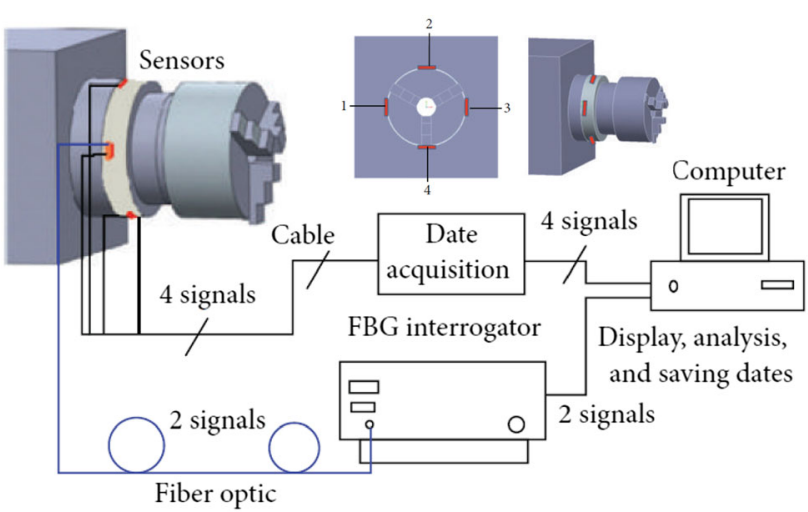

Figure 19 Temperature field measurement of the lathe spindle [97]
Dong, et al. [98], embedded six FBGs connected in one fiber into the spindle housing. These FBGs were installed on the outer ring surface of the front bearing equidistantly in the circumferential direction (shown in Figure 20). With the shaft rotating freely or under radius force, the corresponding uniform or non-uniform temperature field of the outer ring was measured. Additionally, based on the testing, the influence of bearing preload on the temperature rise of the bearing was studied.

\subsubsection{Thermal Error Measurement of a Heavy-Duty CNC Machine Tool Based on the Fiber Bragg Grating Sensors}

Huang, et al. [99], measured the surface temperature field of a heavy-duty machine tool using the fiber Bragg grating temperature sensor (shown in Figure 21). Three fibers engraved with 27 fiber Bragg grating sensors were arranged on the bed, column, motor, spindle box, and gear box (shown in Figure 22). The temperature was monitored for $24 \mathrm{~h}$. The laser displacement sensors were utilized to measure the offset of the tool cutting tip in the directions of $X, Y$, and $Z$. In Figure 23, CH1-10, CH2-1 $\mathrm{CH} 2-7$, and $\mathrm{CH} 3-6$, show the air temperature changes in the different parts of the environment near to the machine tool. The rest show the temperature in different parts of the structure surface of the machine tool. The parts all had the same change trend, but the temperature of the surrounding environment had an effect on the different parts of the machine tool. There was a large temperature gradient on the surface of the structure. Figure 24 shows the relationship of the thermal drift of the tool tip in three directions and the variation of the environmental temperature and the surface temperature of machine tool. The thermal drift in three directions shifted with environmental temperature and machine tool surface temperature. The thermal drift in the $Y$ direction was the largest. When the ambient temperature shift reached about $-6^{\circ} \mathrm{C}$, the error in the direction of $Y$ reached about $15 \mu \mathrm{m}$.

The fiber Bragg grating has the characteristics of multipoint temperature measurement. It can realize the layout of

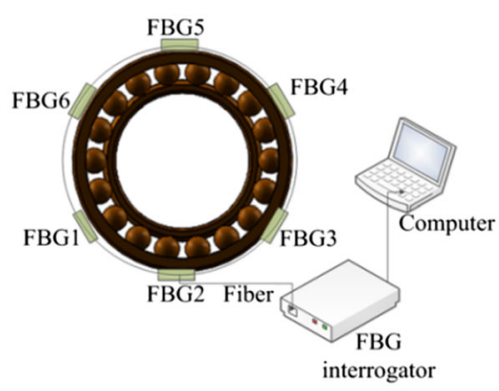

Figure 20 FBG sensors installation locations [98] 
Figure 21 Temperature field measurement of a heavy-duty machine tool based on the FBG [99]

Figure 22 Locations of the FBG temperature sensors [99]

\section{a FBG sensors}
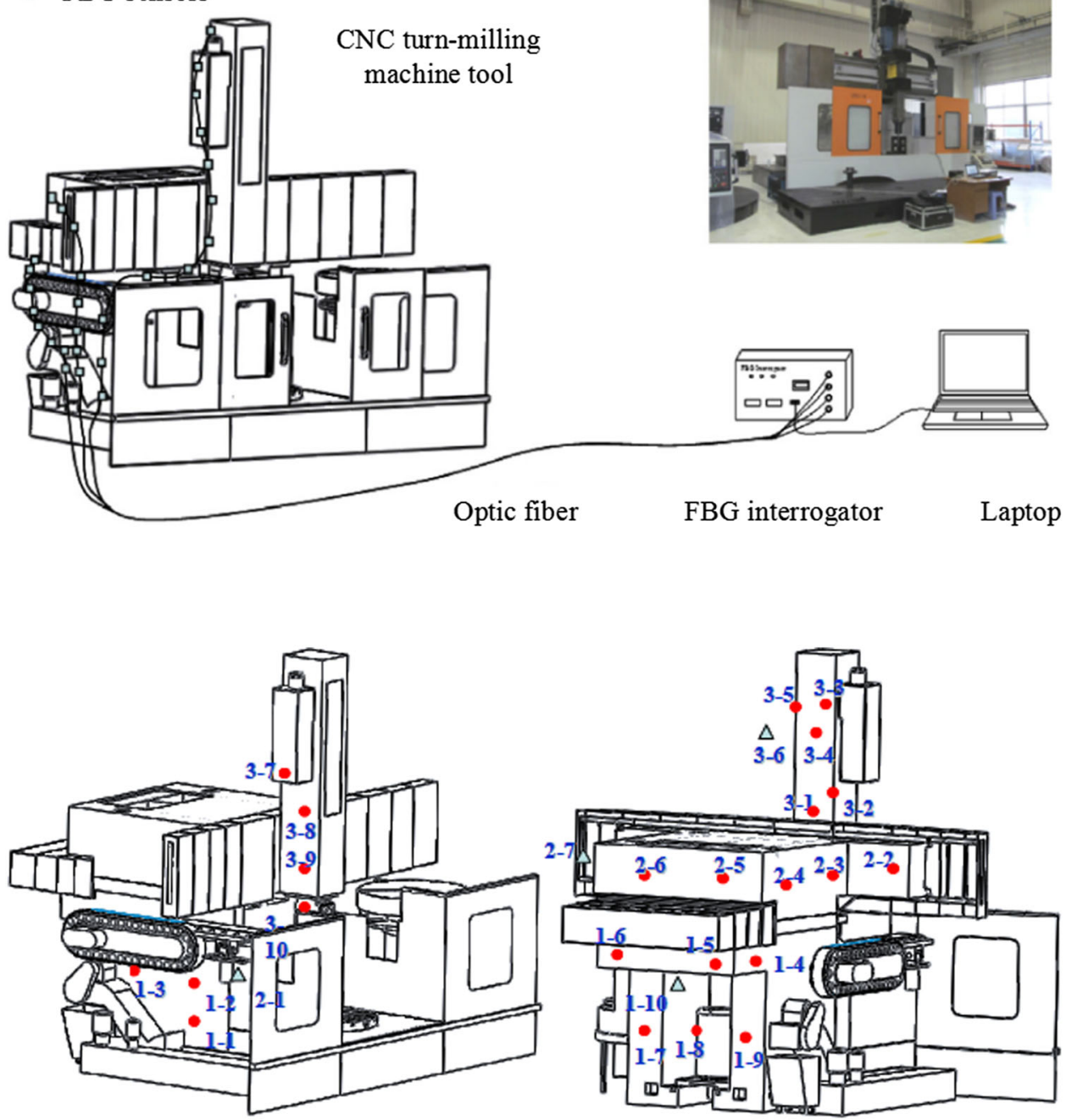

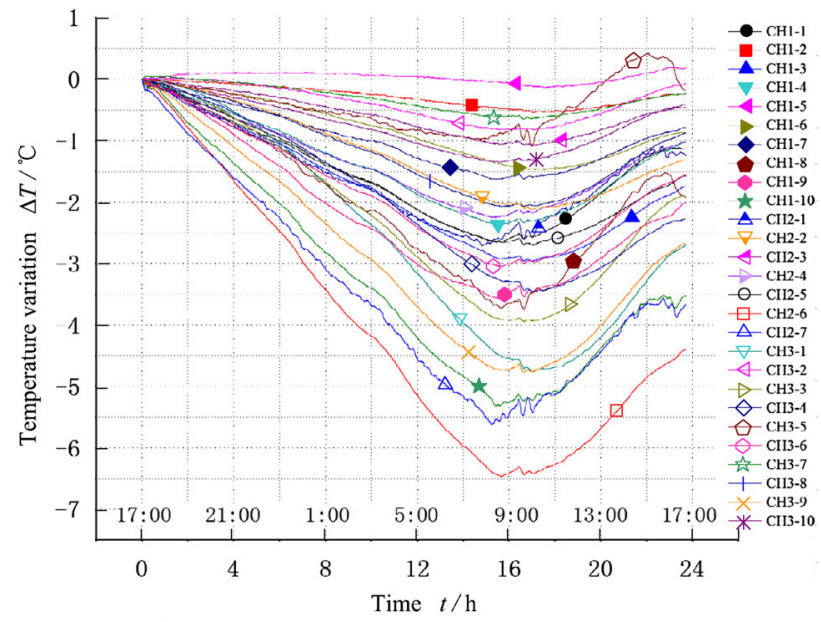

Figure 23 Diurnal variation of the temperature [99]

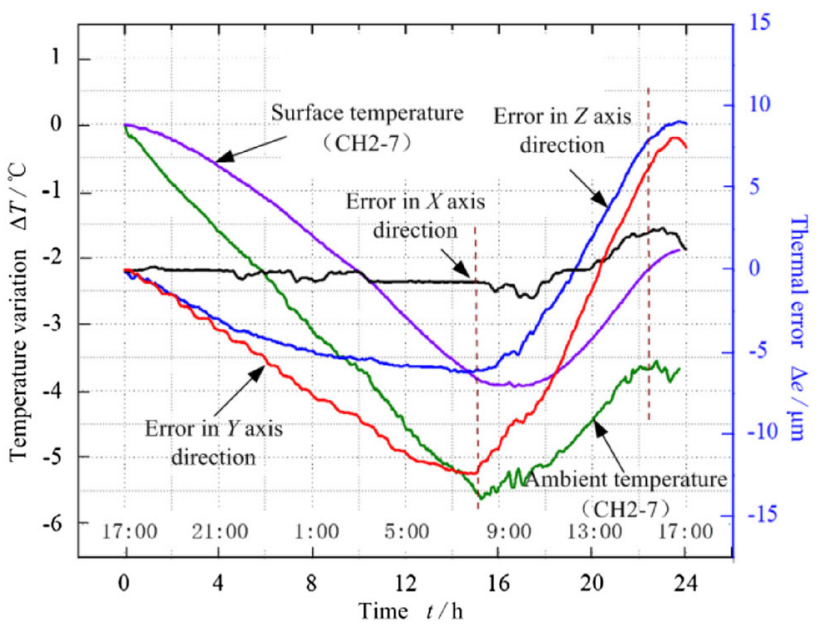

Figure 24 Changes of temperature and the thermal drift [99] 
the temperature measurement points in the large surface area of the heavy-duty $\mathrm{CNC}$ machine tool, which can realize the reconstruction of the temperature field of the machine tool more accurately.

\subsection{Heavy-Duty CNC Machine Tool Thermal Deformation Monitoring Based on Fiber Bragg Grating Sensors}

There have been a number of achievements made in the application of the fiber Bragg grating strain sensor to large structural deformation measurements. By applying the classical beam theory, Kim and Cho [100] rearranged the formula to estimate the continuous deflection profile by using strains measured directly from several points equipped with the fiber Bragg sensor. Their method can be used to measure the deflection curve of bridges, which represents the global behavior of civil structures [101]. Kang, et al. [102], investigated the dynamic structural displacements estimation using the displacement-strain relationship and measured the strain data using fiber Bragg grating. It is confirmed that the structural displacements can be estimated using strain data without displacement measurement. Kang, et al. [103], presented an integrated monitoring scheme for the maglev guideway deflection using wavelength-division-multiplexing (WDM) based fiber Bragg grating sensors, which can effectively avoid EMI in the maglev guideway. Yi, et al. [104], proposed a spatial shape reconstruction method using an orthogonal fiber Bragg grating sensor array.

Fiber Bragg grating sensing technology opens up a new area of study for the real-time thermal deformation monitoring of heavy-duty $\mathrm{CNC}$ machine tool structures. The earliest work was done by Bosetti, et al. [105-107], who put forward a kind of reticular displacement measurement system (RDMS) based on a reticular array of fiber Bragg strain sensors to realize the real-time monitoring of deformations in the structural components of the machine tools (shown in Figure 25).

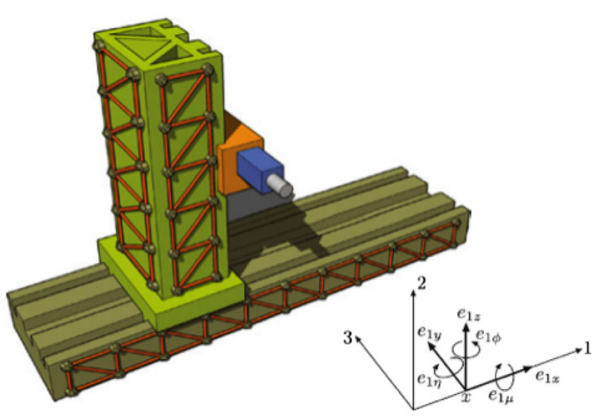

Figure 25 Scheme of a Cartesian milling machine equipped with three RDMSs (typical column height of about 4m) [105]

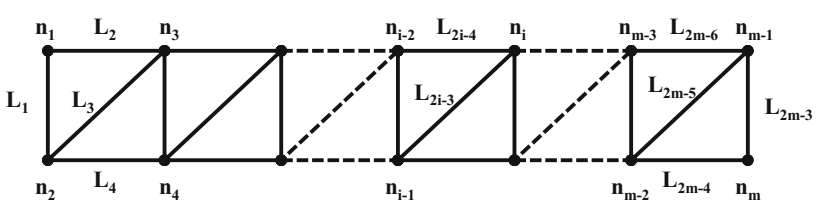

Figure 26 Numbering of the beams and nodes of the lattice [105]

For a planar and isostatic reticular structure (using the numbering conventions shown in Figure 26), the position of the $i$ th node $n_{i}=\left(x_{i}, y_{i}\right)$ can be expressed as a function of the coordinates of the nodes $n_{i-1}$ and $n_{i-2}$ and of the length of the 2 connecting beams $L_{2 i-3}$ and $L_{2 i-4}$ :

$\left\{\begin{array}{l}\left(x_{i}-x_{i-1}\right)^{2}+\left(y_{i}-y_{i-1}\right)^{2}=L_{2 i-3}^{2} \\ \left(x_{i}-x_{i-2}\right)^{2}+\left(y_{i}-y_{i-2}\right)^{2}=L_{2 i-4}^{2} .\end{array}\right.$

Figure 27 shows that the bending deformation of the RDMS prototype reconstructed by the measurement system respectively, which shows good consistency. In order to allow for the development of more general and 3-dimensional structures, a new algorithm was proposed [105]. The problem of calculating the nodal positions on the basis of their distances as measured by the FBG sensors can be reformulated as the a minimization problem.

Liu, et al. [108], detected the thermal deformation of the column of a heavy-duty CNC machine tool with the integral method based on the FBG sensor array (shown in Figure 28). The strain data was gauged by multiple FBG sensors glued on the specified locations of the machine tool, and then transformed into the deformation. The displacement of the machine tool spindle was also gauged for evaluation. The calculation results show consistency with the testing results obtained from the laser displacement sensor (shown in Figure 29). Refs. [109, 110], studied the deformation measurement of heavy-duty $\mathrm{CNC}$ machine tool base using fiber Bragg grating array and designed a FBG-based force transducer for the anchor supporting force measurement of the heavy-duty machine tool base. These research can be extended to the analysis of the

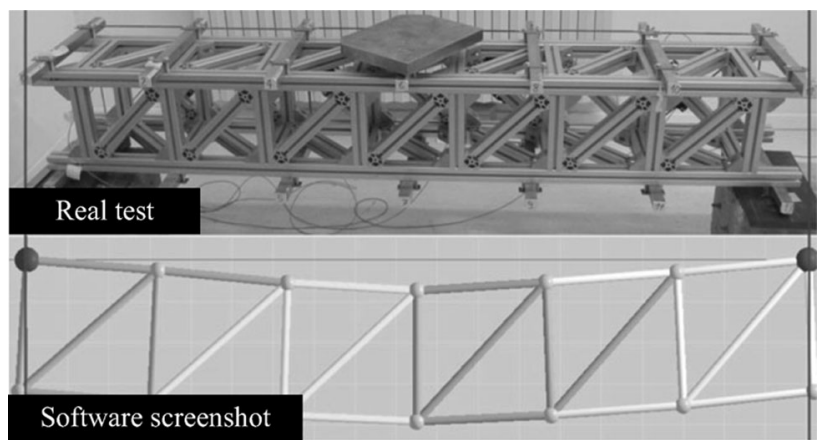

Figure 27 3-point bending of the RDMS prototype and deformed shape as reconstructed by the measurement system [105] 


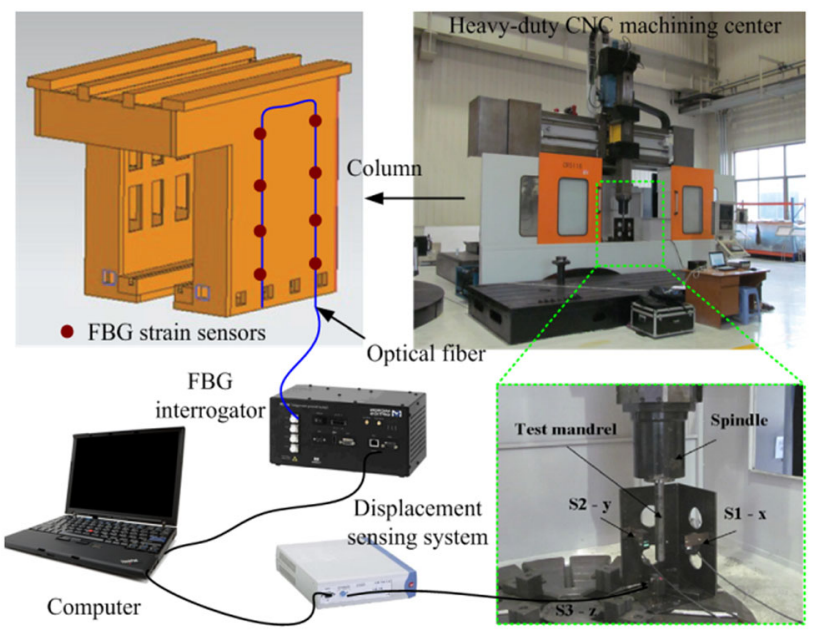

Figure 28 3D models and FBG sensor locations

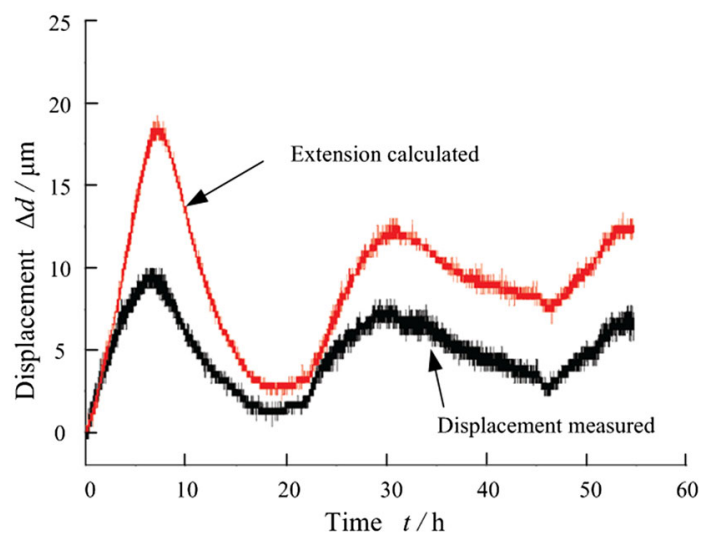

Figure 29 Results calculated by FBG data and results measured by the displacement sensor of the column extension [108]

thermal deformation mechanism and thermal deformation measurement of heavy-duty $\mathrm{CNC}$ machine tool.

\section{Conclusions and Outlook}

The thermal error compensation technology of CNC machine tools has been developed over decades, but its successful application to commercial machine tools is limited. To some extent, it is still in the laboratory stage. Heavy-duty CNC machine tools play an important role in the national economic development and national defense modernization. However, due to the more complex thermal deformation mechanism and difficulty in the monitoring technology caused by a huge volume, overcoming its thermal error problems is extremely difficult.

The fiber Bragg grating sensing technology opens up a new areas of research for thermal error monitoring of heavy-duty CNC machine tools. We need to take advantage of the fiber Bragg grating sensing technology in global temperature fields and thermal deformation field measurements for heavy-duty $\mathrm{CNC}$ machine tool to study the thermal error mechanism of heavy-duty $\mathrm{CNC}$ machine tool. These can provide technological support for thermal structure optimization design of heavy-duty CNC machine tools. We also need to improve the thermal error prediction model, especially in regards to the robustness problem.

Intelligent manufacturing is an important trend in manufacturing technology, and the Industry 4.0 promises to create smart factory [111, 112]. Intelligent sensing technology is one of the indispensable foundations for the realization of intelligent manufacturing. The fusion of optical fiber sensing technology and high-end manufacturing technology is an important research direction that will play an important role in the Industry 4.0.

Open Access This article is distributed under the terms of the Creative Commons Attribution 4.0 International License (http://crea tivecommons.org/licenses/by/4.0/), which permits unrestricted use, distribution, and reproduction in any medium, provided you give appropriate credit to the original author(s) and the source, provide a link to the Creative Commons license, and indicate if changes were made.

\section{References}

1. L Uriarte, M Zatarain, D Axinte, et al. Machine tools for large parts. CIRP Annals - Manufacturing Technology, 2013, 62(2): 731-750.

2. J Bryan. International status of thermal error research. CIRP Annals-Manufacturing Technology, 1990, 39(2): 645-656.

3. J G Yang. Present situation and prospect of error compensation technology for NC machine tool. Aeronautical Manufacturing Technology, 2012, 48(5): 40-45. (in Chinese)

4. C H Wu, Y T Kung. Thermal analysis for the feed drive system of a CNC machine center. International Journal of Machine Tools and Manufacture, 2003, 43(15): 1521-1528.

5. J H Lee, S H Yang. Statistical optimization and assessment of a thermal error model for $\mathrm{CNC}$ machine tools. International Journal of Machine Tools and Manufacture, 2002, 42(1): 147-155.

6. J S Chen, W Y Hsu, Characterizations and models for the thermal growth of a motorized high speed spindle. International Journal of Machine Tools and Manufacture, 2003, 43(11): 1163-1170.

7. S Yang, J Yuan, J Ni. The improvement of thermal error modeling and compensation on machine tools by CMAC neural network. International Journal of Machine Tools and Manufacture, 1996, 36(4): 527-537.

8. C D Mize, J C Ziegert. Neural network thermal error compensation of a machining center. Precision Engineering, 2000, 24(4): 338-346.

9. D S Lee, J Y Choi, D H Choi. ICA based thermal source extraction and thermal distortion compensation method for a machine tool. International Journal of Machine Tools and Manufacture, 2003, 43(6): 589-597.

10. H Yang, J Ni. Dynamic neural network modeling for nonlinear, nonstationary machine tool thermally induced error. 
International Journal of Machine Tools and Manufacture, 2005, 45(4-5): 455-465.

11. Y Kang, C W Chang, Y Huang, et al. Modification of a neural network utilizing hybrid filters for the compensation of thermal deformation in machine tools. International Journal of Machine Tools and Manufacture, 2007, 47(2): 376-387.

12. H Wu, H T Zhang, Q J Guo, et al. Thermal error optimization modeling and real-time compensation on a CNC turning center. Journal of Materials Processing Technology, 2008, 207(1-3): 172-179.

13. Q J Guo, J G Yang, H Wu. Application of ACO-BPN to thermal error modeling of $\mathrm{NC}$ machine tool. The International Journal of Advanced Manufacturing Technology, 2010, 50(5): 667-675.

14. Y Zhang, J G Yang, $H$ Jiang. Machine tool thermal error modeling and prediction by grey neural network. The International Journal of Advanced Manufacturing Technology, 2012, 59(9): 1065-1072.

15. International Organization for Standardization Technical Committees. ISO 230-3-2007 Test code for machine tools-Part 3: Determination of thermal effects. Geneva: International Organization for Standardization, 2007.

16. International Organization for Standardization Technical Committees. ISO 10791-10-2007 Test conditions for machining centres-Part 10: Evaluation of thermal distortion. Geneva: International Organization for Standardization, 2007.

17. International Organization for Standardization Technical Committees. ISO 13041-8-2004 Test conditions for numerically controlled turning machines and turning centres - Part 8: Evaluation of thermal distortions. Geneva: International Organization for Standardization, 2004.

18. M Weck, P Mckeown, R Bonse, et al. Reduction and Compensation of Thermal Errors in Machine Tools. CIRP Annals Manufacturing Technology, 1995, 44(2): 589-598.

19. R Ramesh, M A Mannan, A N Poo. Error compensation in machine tools - a review: Part II: thermal errors. International Journal of Machine Tools and Manufacture, 2000, 40(9): 1257-1284.

20. R Ramesh, M A Mannan, A N Poo. Thermal error measurement and modelling in machine tools.: Part I. Influence of varying operating conditions. International Journal of Machine Tools and Manufacture, 2003, 43(4): 391-404.

21. R Ramesh, M A Mannan, A N Poo, et al. Thermal error measurement and modelling in machine tools. Part II. Hybrid bayesian network-support vector machine model. International Journal of Machine Tools and Manufacture, 2003, 43(4): 405-419.

22. J W Li, W J Zhang, G S Yang, et al. Thermal-error modeling for complex physical systems: the-state-of-arts review. The international Journal of Advanced Manufacturing Technology, 2009, 42(1): 168-179.

23. J Z Fu, X Y Yao, Y He, et al. Development of thermal error compensation technology for NC machine tool. Aeronautical Manufacturing Technology, 2010 (4): 64-66. (in Chinese)

24. J Mayr, J Jedrzejewski, E Uhlmann, et al. Thermal issues in machine tools. CIRP Annals - Manufacturing Technology, 2012, 61(2): 771-791.

25. Y Li, W H Zhao, S H Lan, et al. A review on spindle thermal error compensation in machine Tools. International Journal of Machine Tools and Manufacture, 2015, 95: 20-38.

26. H T Wang, T M Li, L P Wang, et al. Review on thermal error modeling of machine tools. Journal of Mechanical Engineering, 2015, 51(9): 119-128. (in Chinese)

27. A Palmgren, B Ruley. Ball and roller bearing engineering. Philadelphia: SKF Industries, Inc.,1945.

28. T A Harris. Rolling bearing analysis. 4th edition. New York: Wiley, 2001.
29. Z Q Liu, Y H Zhang, H Su. Thermal analysis of high speed rolling bearing. Lubrication and Sealing, 1998, 4: 66-68. (in Chineses)

30. J L Stein, J F Tu. A State-space model for monitoring thermally induced preload in anti-friction spindle bearings of high-speed machine tools. Journal of Dynamic Systems Measurement and Control, 1994, 116(3): 372-386.

31. J H Rumbarger, E G Filetti, D Gubernick, et al. Gas turbine engine main shaft roller bearing system analysis. Journal of Lubrication Technology, 1973, 95(4): 401-416.

32. G C Chen, L Q Wang, L Gu, et al. Heating analysis of the high speed ball bearing, Journal of Aerospace Power, 2007, 22(1): 163-168. (in Chinese)

33. R S Moorthy, V P Raja. An improved analytical model for prediction of heat generation in angular contact ball bearing. Arabian Journal for Science and Engineering, 2014, 39(11): 8111-8119.

34. W M Hannon. Rolling-element bearing heat transfer - part I.: Analytic model. Journal of Tribology, 2015, 137(3): 031102.

35. F P Incroper, D P Dewitt, T L Bergman, et al. Fundamentals of heat and mass transfer. 6th ed. Beijing: Chemical Industry Press, 2011. (in Chinese)

36. B Bossmanns, J F Tu. A thermal model for high speed motorized spindles. International Journal of Machine Tools and Manufacture, 1999, 39(9): 1345-1366.

37. B Bossmanns, J F Tu. A power flow model for high speed motorized spindles - heat generation characterization. Journal of Manufacturing Science and Engineering, 2001,123(3): 494-505.

38. T Holkup, H Cao, P Kolár, et al. Thermo-mechanical model of spindles. CIRP Annals - Manufacturing Technology, 2010, 59(1): 365-368.

39. J Takabi, M M Khonsari. Experimental testing and thermal analysis of ball bearings. Tribology International, 2013, 60(7): 93-103.

40. J Jędrzejewski, Z Kowal, W Kwaśny, et al. High-speed precise machine tools spindle units improving. Journal of Materials Processing Technology, 2005, 162-163: 615-621.

41. K S Kim, D W Lee, S M Lee, et al. A numerical approach to determine the frictional torque and temperature of an angular contact ball bearing in a spindle system. International Journal of Precision Engineering and Manufacturing, 2015, 16(1): 135-142.

42. Z C Du, S Y Yao, J G Yang. Thermal behavior analysis and thermal error compensation for motorized spindle of machine tools. International Journal of Precision Engineering and Manufacturing, 2015, 16(7): 1571-1581.

43. J Y Xia, B Wu, Y M Hu, et al. Experimental research on factors influencing thermal dynamics characteristics of feed system. Precision Engineering, 2010, 34(2): 357-368.

44. Z Z Xu, X J Liu, C H Choi, et al. A study on improvement of ball screw system positioning error with liquid-cooling. International Journal of Precision Engineering and Manufacturing, 2012, 13(12): 2173-2181.

45. W S Yun, S K Kim, D W Cho. Thermal error analysis for a CNC lathe feed drive system. International Journal of Machine Tools and Manufacture, 1999, 39(7): 1087-1101

46. J Mayr, M Ess, S Weikert, et al. Thermal behaviour improvement of linear axis. Proceedings of 11th euspen International Conference, Como, Italy, May 23-26, 2011: 291-294.

47. Z Z Xu, X J Liu, S K Lyu. Study on positioning accuracy of nut/ shaft air cooling ball screw for high-precision feed drive. International Journal of Precision Engineering and Manufacturing, 2014, 15(1): 123-128.

48. S K Kim, D W Cho. Real-time estimation of temperature distribution in a ball-screw system. International Journal of Machine Tools and Manufacture, 1997, 37(4): 451-464. 
49. M F Zaeh, T Oertli, J Milberg. Finite element modelling of ball screw feed drive systems. CIRP Annals - Manufacturing Technology, 2004, 53(2): 289-292.

50. C Jin, B Wu, Y M Hu. Heat generation modeling of ball bearing based on internal load distribution. Tribology International, 2012, 45(1): 8-15.

51. C Jin, B Wu, Y M Hu, et al. Temperature distribution and thermal error prediction of a CNC feed system under varying operating conditions. Precision Engineering, 2015, 77(9-12): 1979-1992.

52. C Jin, B Wu, Y M Hu, et al. Thermal characteristics of a CNC feed system under varying operating conditions. Precision Engineering, 2015, 42(9-12): 151-164.

53. B Tan, X Y Mao, H Q Liu, et al. A thermal error model for large machine tools that considers environmental thermal hysteresis effects. International Journal of Machine Tools and Manufacture, 2014. 82-83(7): 11-20.

54. C X Zhang, F Gao, Y Li. Thermal error characteristic analysis and modeling for machine tools due to time-varying environmental temperature. Precision Engineering, 2017, 47: 231-238.

55. N S Mian, S Fletcher, A P Longstaff, et al. Efficient thermal error prediction in a machine tool using finite element analysis. Measurement Science and Technology, 2011, 22(8): 085107.

56. N S Mian, S Fletcher, A P Longstaff, et al. Efficient estimation by FEA of machine tool distortion due to environmental temperature perturbations. Precision Engineering, 2013, 37(2): 372-379.

57. J F Zhang, P F Feng, CHEN C, et al. A method for thermal performance modeling and simulation of machine tools. The International Journal of Advanced Manufacturing Technology, 2013, 68(5): 1517-1527.

58. J Mayr, S Weikert, Wegener K, et al. Comparing the thermomechanical-behaviour of machine tool frame designs using a FDM-FEA simulation approach. Proceedings of the 22nd Annual ASPE Meeting, Dallas, TX, United states, October 14-19, 2007: 17-20.

59. J Mayr, M Ess, S Weikert, et al. Calculating thermal location and component errors on machine tools. Proceedings of the 24nd Annual ASPE Meeting, Monterey, CA, United states, October 4-9, 2009.

60. J Mayr, M Ess, S Weikert, et al. Compensation of thermal effects on machine tools using a FDEM simulation approach// 9th International Conference and Exhibition on Laser Metrology, Machine Tool, CMM and Robotic Performance, Uxbridge, United kingdom, June 30-July 2, 2009: 38-47.

61. F L M Delbressine, G H J Florussen, L A Schijvenaars, et al. Modelling thermomechanical behaviour of multi-axis machine tools. Precision Engineering, 2006, 30(1): 47-53.

62. J Yang, X S Mei, B Feng, et al. Experiments and simulation of thermal behaviors of the dual-drive servo feed system. Chinese Journal of Mechanical Engineering, 2015, 28(1): 76-87.

63. C Jin, B Wu, Y M Hu. Wavelet neural network based on NARMA-L2 model for prediction of thermal characteristics in a feed system. Chinese Journal of Mechanical Engineering, 2011, 24(1): 33-41.

64. J Zhu, J Ni, A J Shih. Robust machine tool thermal error modeling through thermal mode concept. Journal of Manufacturing Science and Engineering, 2008, 130(6): 061006.

65. F C Li, H T Wang, T M Li. Research on thermal error modeling and prediction of heavy $\mathrm{CNC}$ machine tools. Journal of Mechanical Engineering, 2016, 52(11): 154-160. (in Chinese)

66. C Chen, J F Zhang, Z J Wu, et al. A real-time measurement method of temperature fields and thermal errors in machine tools// Proceeding of the 2010 International Conference on Digital Manufacturing and Automation, Changsha, China. 2010, 1: 100-103.
67. O Horejš, M Mareš, L Novotný, et al. Advanced modeling of thermally induced displacements and its implementation into standard CNC controller of horizontal milling center. Procedia CIRP, 2012, 4: 67-72.

68. J Vyroubal. Compensation of machine tool thermal deformation in spindle axis direction based on decomposition method. Precision Engineering, 2012, 36 (1): 121-127.

69. H J Pahk, S W Lee. Thermal error measurement and real time compensation system for the CNC machine tools incorporating the spindle thermal error and the feed axis thermal error. The International Journal of Advanced Manufacturing Technology, 2002, 20(7): 487-494.

70. H Yang, J Ni. Dynamic modeling for machine tool thermal error compensation. Journal of Manufacturing Science and Engineering, 2003, 125(2): 245-254.

71. D Werschmoeller, X C Li. Measurement of tool internal temperatures in the tool - chip contact region by embedded micro thin film thermocouples. Journal of Manufacturing Processes, 2011, 13(2): 147-152.

72. J Liu, G Chen, C H Ji, et al. An investigation of workpiece temperature variation of helical milling for carbon fiber reinforced plastics (CFRP). International Journal of Machine Tools and Manufacture, 2014, 86(11):89-103.

73. J Qiu, C S Liu, Q W Liu, et al. Thermal errors of planer type NC machine tools and its improvement measures. Journal of Mechanical Engineering, 2012,48(21): 149-157. (in Chinese)

74. C W Wu, C H Tang, C F Chang, et al. Thermal error compensation method for machine center. International Journal of Advanced Manufacturing Technology, 2012, 59(5): 681-689.

75. E Uhlmann, J Hu. Thermal modelling of a high speed motor spindle. Procedia Cirp, 2012, 1: 313-318.

76. T Zhang, W H Ye, R J Liang, et al. Study on thermal behavior analysis of nut/shaft air cooling ball screw for high-precision feed drive. Chinese Journal of Mechanical Engineering, 2013, 26(1): 158-165.

77. American National Standards Institute. ANSI/ASME B5.542005 Methods for Performance Evaluation of Computer Numerically Controlled Machining Centers. Washington: American National Standards Institute, 2005.

78. H Schwenke, W Knapp, H Haitjema, et al. Geometric error measurement and compensation of machines: an update. CIRP Annals - Manufacturing Technology, 2008, 57(2): 660-675.

79. A R J Ruiz, J G Rosas, F S Granja, et al. A real-time tool positioning sensor for machine-tools. Sensors, 2009, 9(10): $7622-7647$.

80. E Gomez-Acedo, A Olarra, L N L D L Calle. A method for thermal characterization and modeling of large gantry-type machine tools. The International Journal of Advanced Мапиfacturing Technology, 2012, 62(9): 875-886.

81. S K Lee, J H Yoo, M S Yang. Effect of thermal deformation on machine tool slide guide motion. Tribology International, 2003, 36(1): 41-47.

82. Z D Zhou, Y G Tan, M Y Liu, et al. Actualities and development on dynamic monitoring and diagnosis with distributed fiber Bragg Grating in mechanical systems. Journal of Mechanical Engineering, 2013, 49(19): 55-69. (in Chinese)

83. H N Li, L Ren. Structural health monitoring based on fiber grating sensing technology. Beijing: China Building Industry Press, 2008. (in Chinese)

84. N Hirayama, Y Sano. Fiber Bragg grating temperature sensor for practical use. ISA Trans, 2000, 39(2): 169-173.

85. D G Kim, H C Kang, J K Pan, et al. Sensitivity enhancement of a fiber Bragg grating temperature sensor combined with a bimetallic strip. Microwave and Optical Technology Letters, 2014, 56(8): 1926-1929. 
86. Y G Zhan. Study on high resolution optical fiber grating temperature sensor research. Chinese Journal of Lasers, 2005, 32(1): 83-86. (in Chinese)

87. W He, X D Xu, D S Jiang. High-sensitivity fiber Bragg grating temperature sensor with polymer jacket and its low-temperature characteristic. Acta Optica Sinica, 2004, 24(10): 1316-1319. (in Chinese)

88. C H Lee, M K Kim, K T Kim, et al. Enhanced temperature sensitivity of fiber Bragg grating temperature sensor using thermal expansion of copper tube. Microwave and Optical Technology Letters, 2011, 53(7): 1669-1671.

89. C Lupi, F Felli, A Brotzu, et al. Improving FBG sensor sensitivity at cryogenic temperature by metal coating. IEEE Sensors Journal, 2008, 8(7): 1299-1304.

90. Y L Li, H Zhang, Y Feng, et al. Metal coating of fiber Bragg grating and the temperature sensing character after metallization. Optical Fiber Technology, 2009, 15(4): 391-397.

91. Y Feng, H Zhang, Y L Li, et al. Temperature sensing of metalcoated fiber Bragg grating. IEEE/ASME Transactions on Mechatronics, 2010, 15(4): 511-519.

92. R S Shen, J Zhang, Y Wang, et al. Study on high-temperature and high-pressure measurement by using metal-coated FBG. Microwave and Optical Technology Letters, 2008, 50(5): $1138-1140$.

93. M J Guo, D S Jiang. Low temperature properties of fiber Bragg grating temperature sensor with plating gold. Chinese Journal of Low Temperature Physics, 2006, 28(2): 138-141. (in Chinese)

94. Y G Zhan, S L Xue, Q Y Yang, et al. A novel fiber Bragg grating high-temperature sensor. Optik - International Journal for Light and Electron Optics, 2008, 119(11): 535-539.

95. Y Liu, Z D Zhou, E L Zhang, et al. Measurement error of surface-mounted fiber Bragg grating temperature sensor. Review of Scientific Instruments, 2014, 85(6): 064905.

96. Y Liu, J Zhang. Model Study of the Influence of ambient temperature and installation types on surface temperature measurement by using a fiber Bragg grating sensor. Sensors, 2016, 16(7): 975.

97. M Y Liu, E L Zhang, Z D Zhou, et al. Measurement of temperature field for the spindle of machine tool based on optical fiber Bragg grating sensors. Advances in Mechanical Engineering, 2013, 2: 940626.

98. Y F Dong, Z D Zhou, Z C Liu, et al. Temperature field measurement of spindle ball bearing under radial force based on fiber Bragg grating sensors. Advances in Mechanical Engineering, 2015, 7(12): 1-6.

99. J Huang, Z D Zhou, M Y Liu, et al. Real-time measurement of temperature field in heavy-duty machine tools using fiber Bragg grating sensors and analysis of thermal shift errors. Mechatronics, 2015, 31: 16-21.

100. N S Kim, N S Cho. Estimating deflection of a simple beam model using fiber optic bragg-grating sensors. Experimental Mechanics, 2004, 44(4): 433-439.

101. S J Chang, N S Kim. Estimation of displacement response from FBG strain sensors using empirical mode decomposition technique. Experimental Mechanics, 2012, 52(6): 573-589.

102. L H Kang, D K Kim, J H Han, Estimation of dynamic structural displacements using fiber Bragg grating strain sensors. Journal of Sound and Vibration, 2007, 305(3): 534-542.

103. D Kang, W Chung. Integrated monitoring scheme for a maglev guideway using multiplexed FBG sensor arrays. NDT \& $E$ International, 2009, 42(4): 260-266.

104. J C Yi, X J Zhu, H S Zhang, et al. Spatial shape reconstruction using orthogonal fiber Bragg grating sensor array. Mechatronics, 2012, 22(6): 679-687.

105. P Bosetti, S Bruschi. Enhancing positioning accuracy of $\mathrm{CNC}$ machine tools by means of direct measurement of deformation.
The International Journal of Advanced Manufacturing Technology, 2012, 58(5-8): 651-662.

106. F Biral, P Bosetti, R Oboe, et al. A new direct deformation sensor for active compensation of positioning errors in large milling machines.9th IEEE International Workshop on Advanced Motion Control, Istanbul, Turkey, March 27-29, 2006: 126-131.

107. F Biral, P Bosetti. On-line measurement and compensation of geometrical errors for Cartesian numerical control machines. 9th IEEE International Workshop on Advanced Motion Control, Istanbul, Turkey, March 27-29, 2006: 120-125.

108. Y Liu, M Y Liu, C X Yi, et al. Measurement of the deformation field for machine tool based on optical fiber Bragg grating sensors. 2014 International Conference on Innovative Design and Manufacturing, Quebec, Canada, August 13-15, 2014: 222-226.

109. R Y Li, Y G Tan, Y Liu, et al. A new deformation measurement method for heavy-duty machine tool base by multipoint distributed FBG sensors. Applied Optics and Photonics, China: Optical Fiber Sensors and Applications (AOPC 2015), Beijing, China, May 5-7, 2015: 967903.

110. R Y Li, Y G Tan, L Hong, et al. A temperature-independent force transducer using one optical fiber with multiple Bragg gratings. IEICE Electronic Express, 2016, 13(10): 20160198.

111. Y Li, Q Liu, R Tong, et al. Shared and service-oriented CNC machining system for intelligent manufacturing process. Chinese Journal of Mechanical Engineering, 2015, 28(6): $1100-1108$

112. R Harrison, D Vera, B Ahmad. Engineering the smart factory. Chinese Journal of Mechanical Engineering, 2016, 29(6): 1046-1051.

Zu-De Zhou, born in 1946, is currently a professor at School of Mechanical and Electronic Engineering, Wuhan University of Technology, China. His research interests include digital manufacturing technology, cloud manufacturing technology, and dynamic monitoring of mechanical system. E-mail: zudezhou@whut.edu.cn

Lin Gui, born in 1962, is currently a senior engineer at Wuhan Heavy Duty Machine Tool Group Corporation, China. His research interests include design of heavy-duty $\mathrm{CNC}$ machine tool. E-mail: 13807117729@139.com

Yue-Gang Tan, born in 1959, is currently a professor at School of Mechanical and Electronic Engineering, Wuhan University of Technology, China. His research interests include under-actuated robot and fiber Bragg grating sensing technology. E-mail: ygtan@whut.edu.cn

Ming-Yao Liu, born in 1963, is currently a professor at School of Mechanical and Electronic Engineering, Wuhan University of Technology, China. His research interests include cutting force monitoring of $\mathrm{CNC}$ machine tool and robot technology. E-mail: 1mylyf@126.com

Yi Liu, born in 1980, is currently a postdoctoral researcher at School of Mechanical and Electronic Engineering, Wuhan University of Technology, China. His research interests include optical sensing technology. E-mail: wgdliuyi2001@126.com

Rui-Ya Li, born in 1988, is currently a PHD candidate at School of Mechanical and Electronic Engineering, Wuhan University of Technology, China. His research interests include thermal error of heavy-duty $\mathrm{CNC}$ machine tool and remanufacturing technology. E-mail: liruiya@whut.edu.cn 